\title{
HOW INTERACTIVE ART INSTALLATIONS CAN BE UTILIZED \\ FOR PRACTICES OF MOURNING
}

\author{
by
}

\begin{abstract}
Tatjana Petkovic
BA in Graphic Design, OCAD University, 2014
\end{abstract}

\author{
A Major Research Paper \\ Presented to Ryerson University \\ in partial fulfillment of the \\ requirements for the degree of \\ Master of Digital Media \\ in the Program of Digital Media
}

Toronto, Ontario, Canada, 2018

(C) Tatjana Petkovic, 2018 


\section{AUTHOR'S DECLARATION FOR ELECTRONIC SUBMISSION OF A MRP}

I hereby declare that I am the sole author of this MRP. This is a true copy of the MRP, including any required final revisions.

I authorize Ryerson University to lend this MRP to other institutions or individuals for the purpose of scholarly research.

I further authorize Ryerson University to reproduce this MRP by photocopying or by

other means, in total or in part, at the request of other institutions or individuals for the purpose of scholarly research.

I understand that my MRP may be made electronically available to the public.

Signed,

Tatjana Petkovic 


\author{
ABSTRACT \\ HOW INTERACTIVE ART INSTALLATIONS CAN BE UTILIZED \\ FOR PRACTICES OF MOURNING \\ Tatjana Petkovic \\ Master of Digital Media \\ Digital Media \\ Ryerson University, 2018
}

This research examines how interactive art installations can facilitate practices of mourning. The paper considers the following questions; 1) How does our relationship with space, time, and art affect how we mourn a deceased loved one? 2) How does space affect the living body when grieving? 3) How does time affect the memory of a departed loved one? 4) How does art therapy as meaning-making benefit the mourning process? The research engages with questions of perception, memory, inner and external space, and the embodied experiences of art. It offers an analysis through a phenomenological and socio-psychological lens of how art can be used to benefit the mourning process. The paper contains case studies examining current art installations and interactive art installations depicting mourning and grief. The paper explores how art and perception create meaning within our sense of self, and how this can benefit the grieving process. 


\section{ACKNOWLEDGEMENTS}

Firstly, I would like to thank my supervisor, Boris Pantev, for his continual support and guidance throughout my research in this graduate program. I appreciate his patience in unpacking specific ideas within phenomenology to help me understand and engage with. I would also like to thank my second reader, Patricio Davila, for his guidance during my Master's degree and his direction and facilitation during the creation of my undergraduate thesis, the interactive art installation, $A$ Constant Revise (2014). I am also appreciative of Roderick Grant, Alya Naumova, Katina Constantinou, and Jennifer Weaymouth for their mentorship before and during my program. I am very grateful to Nathan Whitbourne, for his continual emotional and editing support throughout the program. I would also like to thank Michelle Chan, Emilie Ballay, and Kelvin Lam for their encouragement, support, and editing of my work. I am grateful of the Canadian Institutes of Health Research in the SSHRC scholarship for their belief in my research, as well as Ryerson's Graduate Grant, both of which helped fund this research. I am appreciative of my fellow cohort members for their encouragement throughout the masters program. Lastly, I would like to thank my mother for her support in allowing me to pursue a career in design, art and education. 


\section{DEDICATION}

I would like to dedicate this research to my father, Milivoje Petkovic, for without him, it would not exist. 


\section{TABLE OF CONTENTS}

Author's Declaration__ ii

Abstract

Acknowledgements__ iv

Dedication _ V V

Table of Contents _ vi

List of Tables, Figures, Images___ vii

Introduction 1

Chapter 1: How Art and Our Perception Create Meaning within Our Sense of Self and How This Can Benefit the Grieving Process

Introduction 3

Part I: Space in Relation to Mourning __ 3

Part II: Time in Relation to Mourning 6

Part III: Art Therapy as Meaning-making for Mourning ___ 9

Conclusion 115

References 17

Chapter 2: Art Installation on Mourning Case Studies

Introduction 19

Benefits of Interactive Installations _ 20

Art Installation Case Studies 21

Conclusion 28

References 31

Chapter 3: A Constant Revise

Introduction 33

$\begin{array}{ll}\text { Part I } & 34\end{array}$

Part II

Introduction $\quad 51$

Section 1. Entering The Author's Personal World _ 51

Section II. How Empathy is Created 55

Section III. Reflection on My Mourning Process__ 59

Conclusion $\quad 61$

References 63

Conclusion $\quad 64$

$\begin{array}{lr}\text { References } & 67\end{array}$ 


\section{LIST OF IMAGES}

Chapter 2

Figure 1. Boltanski, C. (1991). Missing House. 22

Figure 2. Gonzalez-Torres, F. (1991). "Untitled" (Portrait of Ross in L.A.). _ 24

Figure 3. Viola, B. (1991). The Passing. — 25

Figure 4. Wilson, A. M. (2016). Itaru Sasaki's Wind Phone. 26

Figure 5. Kubota, N. (2016). Taryn Simon's An Occupation of Loss. ___ 28

Chapter 3, Part 1

Figure 1. Overlapping of time periods. 35

Figure 2. Folded photograph.

Figure 3. Desaturating images. 36

Figure 4. Photocopied Image, loss of clarity. 37

Figure 5. Light explorations in pattern.

Figure 6. Light explorations in pattern and environment.

Figure 7. Tunnel. 38

Figure 8. Folding Light. 39

Figure 9.1. Visual Voids. 40

Figure 9.2. Visual Voids. 41

Figure 10. Unfocused scene._ 42

Figure 11. Two minutes of video sequence. 45

Figure 12. Projected current work in environment. _ـ 48

Figure 13.1. A Constant Revise, Exhibition space.

Figure 13.2. A Constant Revise, Exhibition space.

Figure 13.3. A Constant Revise, Exhibition space. $\longleftarrow 49$ 


\section{INTRODUCTION}

\section{Utilizing Interactive Art Installations for Processes of Mourning}

The grieving process of mourners is often overlooked in society today, as mourning the death of loved ones is still considered a difficult subject matter to bring forth in conversation. The issue of how to cope with loss is still prevalent in our everyday lives, as it affects everyone. More now then ever, traditional frameworks of making sense of experiences pertaining to death and how we mourn, such as religion, culture, and family, have strongly declined in the last few decades. Tutter (2016) describes the importance of remembering loss: "It is not difficult to understand why loss must be 'remembered' at all: often, the fact of loss is for some time incomprehensible, let alone acceptable. Moreover, when we sustain a loss - whether that of our beloved, our home, or our youth — we lose a part of ourselves, at least temporarily, and in some instances, forever" (p. xxvii). Her description suggests that we must mourn not for the dead, but for ourselves. The importance of mourning lies in the complexity of how to cope with the loss as it alters our physical sense of being.

My paper focuses on examining how interactive installations can be utilized for processes of mourning, which I will explore through a phenomenological and socio-psychological lens. I will be focusing on the individual mourning process, and investigate how interactive installations can benefit and address the grieving process of individual or collective spectators.

The work is separated into three chapters. The first chapter explores how art and perception creates meaning within our sense of self, and how this can benefit the mourning process. The research focus engages with questions of memory, inner and external space and 
time, and the embodied experiences of art. It will offer an analysis through a socio-psychological and phenomenological lens of how art and art therapy can be used to benefit the mourning process. The second chapter focuses on case studies of specific interactive installations dealing with mourning or depicting death. It develops a phenomenological analysis of these case studies and examines how they relate to my own installation piece, A Constant Revise (2014). The third chapter is separated into two parts. The first part goes in-depth into the process of creating my digital interactive installation, which explored the question of how time, memory and change in perception alter the identity and knowledge of a departed loved one? This part of the chapter will also analyze the use of digital media as a tool to articulate how video, projection, and the camera lens are able to visualize the mourning process. The second part of that chapter analyzes my interactive installation through a phenomenological lens, and places a specific emphasis on the ways it motivates empathy. I reflect on my personal experience of using meaning-making as a process of mourning through the creation of my interactive installation. I will conclude with an account of how the social aspects of interactive installations have positive effects on a community. 


\section{CHAPTER 1}

How Art and Our Perception Creates Meaning within Our Sense of Self, and How This Can Benefit the Grieving Process

\section{Introduction}

Death is an inevitable part of life that affects everyone. When the death of a loved one arrives, we lose not only a physical being, but also the relationship with the deceased; the mourners' sense of self changes as they try to find meaning in the absence of their departed companion when dealing with their loss. Throughout this chapter, I will ask the following question: How does our relationship with space, time, and art affect and benefit how we mourn a deceased loved one? I will argue that in this process of transformation, meaning is constructed through experiencing and creating art, which benefits the mourner in their adjustment to their loss. In Part 1, I will explore this question by first asking how space affects the living body when grieving. In Part 2, I will develop the question of how time affects the memory of a departed loved one. Part 3 will conclude the chapter by discussing how art therapy as meaning-making can affect and benefit the mourning process. I will explore these questions through a phenomenological and socio-psychological lens.

\section{Part I}

Space in Relation to Mourning

First, I will examine how space affects the body when grieving from a phenomenological perspective. Merleau-Ponty (2002) describes how the interaction of the body and space creates an embodied experience, which connects the senses of the body with the space itself (p. 235). There is a difference between a bird's eye view of a space and being physically in the space 
(Merleau-Ponty, 2002, p. 235). Merleau-Ponty (2002) compares the heart inside the organism to our body within the world (p. 235). We are therefore always in relation to a space, and a space will always affect us. Having your body physically present within a space allows you to experience the space in different perspectives, allowing different views of objects, and different movements of yourself in relation to those objects (Merleau-Ponty, 2002, p. 235). Our bodies are always in space.

The body's physical ability to retain specific memories, also known as haptic memory, makes people re-enact certain mental states when they encounter familiar objects or find themselves in the same space they have been before. I will later explore how the presence of the deceased is sensed in a lived body when moving through a previous shared space, as shared memories are embedded in that physical space.

The body's physical memory then affects the body's mental memory, triggering certain memories based on familiar spaces or objects. Objects and spaces can evoke memories of our deceased loved ones or the idea of death itself (Hallam \& Hockey, 2006, p.80). Our body is how we perceive the world, it is the subject of perception, and the way we acquire our sense of self (Merleau-Ponty, 2002, p. 239). Therefore, how we perceive the space around us is part of our identity, as it affects our mind and physical_body.

Spaces affect the body differently when grieving the loss of a loved one. Fuchs (2017) claims the body searches for their departed loved one in familiar places, as the presence of the deceased can still be felt (Fuchs, p. 53). The mourner retains the memory of the loved one within their own body and lived space, and after the event of death, the loss can be felt within both these aspects (Fuchs, 2017, p. 47). If perceiving spaces around us forms part of our identity, then our identity changes once the death of a loved one is experienced. The mourner's previous world has 
changed, and therefore, the sense of self within the mourner is different as their perception of time, self and space alters (Fuchs, 2017, p. 44). The loss of the loved one reflects upon the mourner as a partial loss of self, as our sense of self is cultivated through our differentiation, connection and interaction with others (Fuchs, 2017, p. 48). Casey (2009) goes further into detail on this concept, stating that we identify ourselves based on the places where we live or reside (p. 120). Our places tend to exist in our image, but we also take on certain physical properties of our living space, for example, being "straight", "sinuous", "expansive” or "reclusive” (Casey, 2009, p. 120). The longer we reside in a space, the more we feel "at home," and the more we tend to see our homes as extensions of ourselves (Casey, p. 120). I would contend that the homes we shared with loved ones, and that we continue to live in after their passing, becomes a representation of our relationship we shared with them, as well as our changed identity without them. A sense of loss is not only felt in our living bodily state, but also felt through a physical sense of loss. The objects we associate with them now become mementos of their death in the space. How we walk through a previously shared space becomes a reminder and memory of where we interacted and existed with the deceased.

Specific spaces of mourning, such as cemeteries or events (the act of scattering ashes or a commemorative speech of a loved one), create an embodied experience for us (Hallam \& Hockey, 2006, p.80). We begin to associate our departed loved ones with these spaces, making us further readjust our understanding of our new relationship with them after their death. We react sensually, emotionally and psychologically in these new spaces of mourning (Hallam \& Hockey, 2006, p.80). These different spaces of mourning (gravesite, or ritual space), help us distinguish that our loved ones' identities no longer reside in our other, everyday spaces. The mourner is experiencing a change in identity during their grieving period through their physical 
and mental space, and is searching for meaning within these specific spaces to make sense of the death. Therefore, the body is trying to find meaning within a specific space of mourning by understanding their own changed personal identity, with the loss of their loved one.

\section{Part II}

Time in Relation to Mourning

Secondly, I will investigate, from a phenomenological perspective, how time affects the memory of a departed loved one. Brough (1975) clarifies Husserl's ideas on memory, in that for memory to exist, it would have had to be perceived in the present Now (p. 41). Brough (1975) describes past as something that has been experienced as "present", which implies that the past is no longer present (p. 41). This means that our memories are our representations of our past "present" experiences that we perceived, and our current present is whatever we are currently perceiving in the present Now. Our present Now can perceive our memories of the past "present", but it is not our current present Now. In this sense, I would state that our past memories of our loved ones carry the weight that the deceased are no longer present in our "present" world, but only in fact, in memory. This means that we can sometimes misunderstand our current present with memories of our past "present", making us not fully understand that our deceased loved ones are no longer living with us in the present time. The connection between the past and present is needed in memory to understand the past, without it, the past would not be the "past," but a false perception of what is past (Brough, 1975, p. 42).

Fuchs (2017) delves into how the perception of time becomes disconnected after the loss of a loved one, as the present sharply turns into a lost and absolute past (Fuchs, p. 50). The 
mourner then feels in-between two time frames, Now and "no longer", as their personal reality cannot accept the "pastness of the past" while the current world time passes and threatens to separate them from their past loved one which sinks further into the past (Fuchs, 2017, p. 50). Memory then clouds the mourner of their perception of time, as memories can still be quite vivid, as if the loved one had never departed (Fuchs, 2017, p. 50). These two perceptions of time co-exist, and it is as if the mourner is living in two different worlds (Fuchs, 2017, p. 50). One world is that of the past that is still present in the mourner's life, and the other is the current present without the departed loved one (Fuchs, 2017, p. 50). Denial then plays a role for the griever, as they cannot accept the current reality of the current world time (Fuchs, 2017, p. 51). These conflicting perceptions of time can cause time to feel as though it is has come to a standstill (Fuchs, 2017, p.51). The future is challenged as it is no longer seen as open as before, as the death of the loved one now limits the expectations of events or possibilities of that relationship, because the loved one is no longer a part of it (Fuchs, 2017, p. 51). The perception of time creates a false sense of reality, where I would argue the mourner is then inclined to search for meaning, or a sense of reason behind the death in order to accept the current reality or truth. The passing of time is needed to re-adjust to the real world without the loved one (Fuchs, 2017, p. 55). This would include repeated experiences of the absence of the person in the mourner's life, and a rejection of the mourner's expectations of their loved one returning (Fuchs, 2017, p.55).

Memory is seen as a representation of the past (Brough, 1975, p. 46). This means that it is not the actual past, and does not necessarily mean an actual fact, but is simply what we perceived to be the past. Our memory is a representation of the past through our own perception. Brough (1975) describes prominence within time as "events in the world's time [that] are brought to 
presence through the intentional experiences which unfold in inner time" (p. 44). This goes back to Husserl's thoughts that something must have been fully present, and you must have perceived it in order for it to be remembered (Brough, 1975, p. 54). Memory is then made up of important, purposeful, meaningful experiences, events or a subject from the past that you are personally connected to. We remember what is meaningful to us. Memory creates a sense of self, based on our personal experiences and history (Brough, 1975, p. 55). Brough states that "without memory we would have no access to what has been the length and breadth of our lives. That time's flow does not imprison the self in a present without windows to the past, we owe to memory" (Brough, 1975, p. 60). If our memory is a representation of our past, as well as a representation of ourselves, our deceased loved ones are part of our personal history, and therefore part of our sense of self. Our shared experiences with our past loved ones make up our memories, which is essential to our personal identity.

We must also consider that how we experience and remember the identity of our loved ones might change through time, as we will then accept their death, and try to sustain and reshape the relationship with them (Fuchs, 2017, p. 60). This can sometimes be seen through commemoration or symbols of the loved one (Fuchs, 2017, p. 60). Symbolism is needed in maintaining the relationship with the deceased, as it opens up an inner space within the mourner to understand the ambiguity of their grieving process by denying the material presence of the deceased, but accepting their symbolic presence (Fuchs, 2017, p. 60). In the next section I will argue that the symbolism in commemorating the loved one is a form of meaning-making, as it allows the mourner to make sense of their loss by remembering the death and understanding an object or symbol has developed a different meaning because of the event in time. 


\section{Part III}

\section{Art Therapy as Meaning-making for Mourning}

In this section, I will explore how art therapy as meaning-making benefits the mourning process. I will contend that art can be used as a tool to help cope with grief, and that it can be seen as a meaning-making process. Art therapy can be used to deal with grief and loss either by the creator of the work herself, or the by the individual experiencing the work. I will explore how meaningmaking as art therapy consists of the physical therapeutic act of an artist forming their thoughts, ideas, and emotions through the tools that they use, as well as the induced reflective state on the mourner's experience, either through creating the artwork or experiencing an artwork.

Art has been seen to aid the artist and relieve the distress caused by the emotional work of mourning (Malchiodi, 2010, p.143). The act of creating meaning with art about death has been around since humans existed, to help cope with the loss (Malchiodi, 2010, p.143). This can be seen through the use of symbols or images in funeral ceremonies since the time of the Neanderthals (i.e. 40,000 years and earlier) done in order to relieve trauma caused by the death of close people (Malchiodi, 2010, p.143).

Meaning-making as a form of art can be used as a tool to help the mourner cope with their grief. Neimeyer (2006) uses a socio-psychological lens in his work to develop a new model for theorizing grief that places meaning-creation at the foreground for coping with a loss ( $\mathrm{p}$. 184). He explains this approach as understanding "human beings as inveterate meaning-makers, weavers of narratives that give thematic significance to the plot structures of their lives (Neimeyer, 2006, p. 184)". MacKenzie and Baumeister (2014) define meaning as "a shared mental representation of possible relationships among things, relationships, and events. Thus, meaning is the basis of a collective, organized network of concepts" (p. 26). I would also insist 
that meaning-making could be applied as art therapy to the mourner. Art is usually considered a meaning-creation process, where the artist expresses their emotions and ideas through different forms of materials. What grievers receive from their experience of meaning-making, is a restructured perspective on their loss to add value to their lives. The action of meaning-making aids the mourner to make sense of the loss, which has been seen as a positive adjustment in their grieving process (Neimeyer, 2006, p. 183). Neimeyer (2006) suggests that forms of reflective journaling and biographical techniques can be shared with others, which in turn, can help the mourner position themselves within the context of their own self-narrative after the loss (p. 186). The sharing aspect of biographical techniques then creates meaning from grief that cannot only help the mourner through their grief, but also others in similar positions.

Art is a form of meaning-making that benefits the mourning process. Merleau-Ponty (2004) describes our phenomenological experience with art as one that "aspires to learn to see the world once more" (p. 93). Art is an object of perception, where you must stand in its special presence in order to experience it (2004, p. 95). The viewer may not be able to understand all signs and meaning within the art piece, but the act of the physical body viewing the work creates its own perceptual experience for the viewer (Merleau-Ponty, 2004, p. 95). Building upon Merleau-Ponty's theory, I would argue that art is the creation of meaning to make sense of the world. Our experience with art is one that affects the physical and mental body through the physical act of making and experiencing. Merleau-Ponty (1996) describes an artist creating as lending their body to the world and changing that world into their creation (p. 123). A created work such as an image is not a copy of the actual world, but an interpretation which holds something that is absent from the actual world, a reflection of an inner gaze (Mereau-Ponty, 1996, p. 126). 
The process of making art creates an embodied experience for the mourner. When an artist creates, a connection between the maker and the tool takes place, using their senses, past experiences and thoughts to create a work. Using art as a method of inquiry allows the maker to think through the material they use (Ingold, 2013, p.6). The artist is then able to work through their ideas or thoughts by experimenting with the material at hand, seeing where it leads (Ingold, 2013, p.6). I would argue that this would assist the mourner through understanding their grief better, as some may not be able to fully process their emotions and thoughts in words. If a mourner uses meaning-making in a form of art as a tool to cope with their grief, the mourner has an increased understanding of the events surrounding the loss of their loved ones and how it impacted their self-esteem or emotional health (Weiskittle \& Gramling, 2018, p.16). Different art forms such as poetry, visual arts, performance, etc. can help a mourner cope as they allow a wider scope of expression than conventional language, giving them an outlet to express a difficult situation, emotion, or feeling when going through grief (Berger \& Thompson, 2011, p. 305). The sensory act of making puts the body in an open state, which can allow meaning to emerge through images, poems or performance (Berger \& Thompson, 2011, p. 305). The mourner can use art to help visualize and process their current reality, current relationship with the deceased, and their current identity. An art-based grief study stated that participants felt a continued bond with the deceased, and it helped them "witness the reality" when using art-based practices to visualize their relationship (such as a scrapbook of family photos, or a drawn family portrait) (Weiskittle \& Gramling, 2018, p.16). The mourning process through art then becomes a reflective process of self. The artist uses her body and mind within a work, and a work then becomes a type of image of self and how the artist perceives a situation (Pallasmaa, p.142). The 
act of making allows the artist to transform their experiences literally and metaphorically (Berger \& Thompson, 2011, p. 306). Meaning-making as art therapy can then be used as a type of reflection on the individual, and a reconstruction of their identity without their lost loved one.

The interaction of art and space has an embodied effect on the mourner. An artistic work that we interact with is a series of complex images, experiences, and emotions that affect our consciousness (Pallasmaa, 2009, p. 127). Studies on art appreciation of individuals have shown that art experiences can be gratifying, as viewing art allows the individual to get a new perspective and provokes an embodied experience of different emotions (Roald, 2008, p. 194). A study interviewing viewers on their interactions with artwork have shown that people experience art in qualitatively different ways, based in respect to both the form and the content of the work (Roald, 2008, p. 207). One experience that artwork can provide, is the enjoyment of beauty. This enjoyment can lead to meaning-creating forces that can help a person reflect, appreciate the experience, and acquire a motivation to live where the person looks for more meaningful experiences that revolve around the pleasure of experiencing art (Roald, 2008, p. 208). Another experience is in understanding the artwork and the idea behind the work, which can take a form of learning (Roald, 2008, p. 208). The viewer usually compares and contrasts their own personal knowledge with that of the art piece, which can prompt emotions (Roald, 2008, p. 209). A third type of experience is a person's body reacting to an art piece emotionally (Roald, 2008, p. 209). This experience is a type of embodied, unconscious reaction to an artwork, which can give a range of emotions to a viewer such as fear, discomfort, joy or elation (Roald, 2008, p. 209). The viewer shares and experiences the emotional presentations within the art piece (p. 209). The act of viewing art is one that is unique to an individual because they are carrying their past experiences, memories, and personal perception within their body, mentally and physically 
effecting how they experience an art piece through their senses. Art appreciation as an experience is seen as a characteristic that defines us as human beings (p. 209). The benefit of experiencing art is the unique, personal experience of viewing and experiencing art for the sake of itself.

A reflective process is not only true for the artist creating their artwork, but for the viewer appreciating or experiencing the artwork. Heidegger describes the experience of art appreciation in a phenomenological perspective as one that reveals the individual's and the culture's existence, as well as their history and past (Roald, 2008, p. 195). Experiencing art also brings forth a different mode of understanding or recognition to the viewer in comparison to their everyday existence (Roald, 2008, p. 195). One way that art prompts this type of reflection to come forth is that it unveils a type of truth, making truth available as an experience (Roald, 2008, p. 195). Heidegger describes truth not in an aesthetic representational sense, but as something that is revealed when also showing the unrevealed, an in-between amongst the open and hidden (Roald, 2008, p. 194). Heidegger uses the example of the ancient Greek's mode of existence, where the creation of their temple revealed the God (as a symbol), based on the creation of the Greeks' values and identities (Roald, 2008, p. 194). God remained hidden before this, as the temple is seen as a form of art, unveiling the Greek values and identities through the creation of the temple and experience of it (Roald, 2008, p. 194). Art therefore shows a type of truth to the viewer, which can cause the viewer to self-reflect on how the truth affects them. In contrast to Heidegger, Merleau-Ponty views art as an "experience, exaltation and recreation" of the world that affects the body (Roald, 2008, p. 198). Similar to Heidegger, Merleau-Ponty also emphasizes the "reveal" of artwork, which can bring a new understanding and perspective of the world (Roald, 2008, p. 198). We might not necessarily be aware of this new understanding or 
perspective, but our bodies can still experience them (p. 198). Reflection can be seen as a benefit of experiencing artwork, as it prompts the viewer to personally reflect on their self, based on their own personal knowledge. I would contend that if a mourner does not create something of meaning to help their self grieve (such as a form of art), they might seek different forms of meaning to help understand their grief by experiencing it.

Specifically, mourners might pursue art to view and discuss ideas and concepts that communicate the experience of death to better understand their own personal grieving process. When the mourner can immerse themselves in art or an art form that shares to their own personal experience with others, they can accept the void in their lives knowing that others have gone through a similar experience and that isolation is not at the forefront of their coping process.

Fuchs (2017) describes the bereavement experience at the level of the body as resembling trauma or a physical accident (Fuchs, p. 45). The body can experience numbness, shock, and a type of paralysis upon the first knowledge of the death of a loved one (Fuchs, 2017, p. 45). After time, the mourner feels similar symptoms of depression, such as added weight to their body, constant pressure on their chest, shortness of breath, and respiratory spasms (Fuchs, 2017, p. 45). The division between physical and psychological pain of the mourner's body is blurred during grief, making the mourner take the death as an injury to the living body, as well at the emotional self (Fuchs, 2017, p. 46). At first, the mourner's body still perceives the lost loved one as present, and therefore, may experience a type of time standstill until the reality of the death comes into focus (Fuchs, 2017, p. 52). Their body then searches for the missing body of the dead within their body memory of how they interacted with them such as speech, touch, embracement, or sexual encounters (Fuchs, 2017, p. 47). The mourner is searching for meaning to make sense of their loss. A gradual adjustment is needed for the mourner to accept the loss of their loved one 
through the reoccurring experiences of their absence (Fuchs, 2017, p. 55). The bereaved must undergo a process of transformation to understand the change in their world and make sense of their loss (Fuchs, p. 55). This transformation can be seen as establishing a new relationship with the deceased in two ways: first, accepting the deceased as a part of themselves through integration and identification; and second, through different ways of representing the deceased, such as through recollection or by symbolization (Fuchs, p. 55). This is quite similar to Neimeyer's (2006) theory of meaning reconstruction in order to maintain and make sense of the relationship with the deceased. The act of representing, remembering, recollecting and symbolizing the memory of a deceased loved one helps demonstrate that the loss is acknowledged (Fuchs, 2017, p. 58). Meaning-making as art therapy can help the mourner through their grieving process by understanding the death of their lost loved one, their new identities without them, expressing their current emotions, and maintaining a relationship with the deceased.

\section{Conclusion}

The mourner's relationship to space, time, and their search for meaning constructs the mourner's new identity and sense of self without their departed loved one. This can be seen through how a mourner's living body interacts with space, how the memory of the deceased loved one and their death is processed through time, and how meaning is constructed through the embodied experience of viewing and creating art, which benefits the mourner's adjustment to their loss.

Merleau-Ponty $(2002,2004)$ was a student of Husserl's, and draws upon his theory of time in his work. How Merleau-Ponty’s $(1996,2002,2004)$ phenomenological perspective 
differs from Husserl is his theory on how perception affects our understanding and experience of the world. What is absent in Merleau-Ponty's $(1996,2002,2004)$ concept is how different stages of life and emotions affect our body and perception. Brough's (1975) study on Husserl does not expand thoroughly on how our memory is a representation of self. Neimeyer's (2006) focus is on grief therapy, and how meaning reconstruction can aid mourners in their mourning process. Fuchs (2017) researches both the psychological and phenomenological perspectives of grief, which interprets the ideas of Husserl, Merleau-Ponty and Neimeyer on the body's perception in the context of seeking meaning in loss and grieving. What we can conclude from these theorists is that perception is a powerful tool to help aid us in the construction of our sense of self. Meaning is derived not only from our memory but also from our perception through our living body. The spaces we inhabit or move through are also a reflection of our identity through how we perceive them. The creation of meaning or the act of seeking meaning can help mourners with the grief of their loved ones. This requires the mourner to accept the loss and retain an integration of the loved one's identity and how the loss fits within their new personal identity without them. Time is seen differently when coping with the loss of a loved one, as the mourner is stuck in-between the past and present. Time can benefit the mourner in accepting their loved one's death with the constant exposure to the absence of their loved one, as it becomes more permanent. Lastly, art can play a role of meaning-making to help mourners deal with the loss of their loved ones, whether through creating art themselves, or through experiencing art to seek meaning. The embodied experience of art prompts the mourner to reflect on their current situation and readjust their current identity, accepting the death of their loved ones, but also maintaining a bond with them through meaning creation, recollection, remembrance and symbolism. 


\section{References}

Berger, J. and Thompson, B. (2011). Grief and Expressive Art Therapy In Niemeyer (Eds.), Grief and bereavement in contemporary society: Bridging research and practice. (pp. 303-313) New York: Routledge.

Brough, J.B. (1975) Husserl on memory. The Monist, 59(1), 40-62.

Casey, E. (2010). Getting back into place: toward a renewed understanding of the place-world. Bloomington, IN: Indiana Univ. Press.

Fuchs, T. (2017). Presence in absence. The ambiguous phenomenology of grief. Phenomenology and the Cognitive Sciences, 17(1), 43-63. doi:10.1007/s11097-017-9506-2

Hallam, E. M., \& Hockey, J. L. (2006). Death, memory and material culture. Oxford: Berg. Ingold, T. (2013). Making: anthropology, archaeology, art and architecture. Milton Park: Abingdon, Oxon.

Pallasmaa, J. (2014). The eyes of the skin: architecture and the senses. Chichester: Wiley.

Lacy, S. (1994). Cultural Pilgrimages and Metaphoric Journeys. In S. Lacy (Ed.), Mapping the Terrain: New Genre Public Art, Seattle-Washington: Bay Press.

MacKenzie, M. J., \& Baumeister, R. F. (2014). Meaning in life: Nature, needs, and myths. In A. Batthyana \& P. Russo-Netzer (Eds.), Meaning in positive and existential psychology (pp. 25-37). New York, NY: Springer. http://dx.doi.org/10.1007/978-1-4939-0308-5_2

Malchiodi, C. A. (2010). The art therapy sourcebook. New York: McGraw-Hill.

Merleau-Ponty, M. (1996). Eye and Mind. In The Merleau-Ponty aesthetics reader: Philosophy and painting (G. A. Johnson, Ed.), (pp. 121-164). Evanston, IL: Northwestern University Press.

Merleau-Ponty, M. (2002). Phenomenology of perception. (Colin Smith, Trans.), 235-240. London: Routledge.

Merleau-Ponty, M. (2004). The world of perception. (Oliver Davis, Trans.) 91-102. London: Routledge.

Neimeyer, R. (2006). Grief, loss, and the quest for meaning. Hellenic Journal of Psychology, 3, 181-188. 
Roald, T. (2008). Toward a Phenomenological Psychology of Art Appreciation. Journal of Phenomenological Psychology, 39(2), 189-212. doi:10.1163/156916208x338783

Willis, K. S., Roussos, G., Chorianopoulos, K., \& Struppek, M. (2010). Shared Encounters. In K. S. Willis, G. Roussos, K. Chorianopoulos, \& M. Struppek (Eds.), Shared Encounters (pp. 1-15). London: Springer.

Weiskittle, R., \& Gramling, S. (2018). The therapeutic effectiveness of using visual art modalities with the bereaved: A systematic review. Psychology Research and Behavior Management, Volume 11, 9-24. doi:10.2147/prbm.s131993 


\section{CHAPTER 2}

\section{Introduction}

In this chapter, I will look into how art installations can benefit the mourning process through a social aspect, and how specific artists use the mourning process to create art installations. When analyzing the artists' works, I will ask how the signs and symbols, as well as the embodied affects of the installation comprehend and illustrate mourning, death, or absence. I will contend that the signs and symbols within an installation affect the embodied experience to take place. I will explore how these art installations connect to the mourning process and their audiences. These artists' perspectives vary from a singular view on mourning, to a collective representation. I will look into works of mourning from artists Christian Boltanski (1990), Felix Gonzalez Torres (1991), Bill Viola (1991), Itaru Sasaki (2016) and Taryn Simon (2016). I will also compare and contrast each art installations with my own work, A Constant Revise (2014). I will first use this definition of art: "Art itself may be understood as product of the human need to remake the world in search of deeper understanding." (Glynn, 2016, p. 7) I will then define art installations using the Tate museum's (n.d.) definition:

Large-scale, mixed-media constructions, often designed for a specific place or for a temporary period of time. Installation artworks (also sometimes described as 'environments') often occupy an entire room or gallery space that the spectator has to walk through in order to engage fully with the work of art. Some installations, however, are designed simply to be walked around and contemplated, or are so fragile that they can only be viewed from a doorway, or one end of a room. What makes installation art different from sculpture or other traditional art forms is that it is a complete unified 
experience, rather than a display of separate, individual artworks. The focus on how the viewer experiences the work and the desire to provide an intense experience for them is a dominant theme in installation art ("Installation Art").

I will finally define "interactive" through Haque (2006), "interaction concerns exchange of information between people, machines, or between a person and a machine... the transactions should be circular and thus create a 'multiple-loop' interaction, depending on the 'conversational creativity' of both interacting systems" (as cited in Urbanowicz \& Nyka, 2016, p. 593). Although not all of the art installations I will be analysing are considered "interactive" by Haque (2006), they all attempt to communicate mourning and grief through space.

\section{Benefits of Interactive Art Installations}

Art installations have been shown to have positive effects on society, as people can interact with the work, as well as engage in discussions with others. Katarzyna Urbanowicz and Lucyna Nyka (2016) have investigated through a sociocultural lens how interactive installations can benefit society. They claim that media and interactive art can positively affect the urban community and architecture by attracting more public interaction socially and physically which would then create a better communal identity (p. 591). Urbanowicz and Nyka (2016) go deeper into detail by saying that there are "astonishing and surprising positive effects on people's perception, feelings and behaviour (p. 591). Public interactive installations change the passive viewer to an active participant, allowing people to get more involved in the space (Urbanowicz \& Nyka, 2016, p. 591). The participants also naturally create shared experiences with other participants experiencing the work, such as shared smiles, conversation, discussion or interaction, creating a sense of community centered around the work (p. 594). This type of 
engagement can facilitate discussions on the work. Mourners specifically are able to reflect on their personal grieving process and acquire a new space for discussion for their very personal and difficult situation. Spaces that are specific to death, such as art installations on mourning, can create a sense of community between mourners, through the use of physical shared space and objects of memory (Hallam and Hockey, 2006).

Art Installations on Mourning Case Studies

\section{Christian Boltanski’s Missing House (1990)}

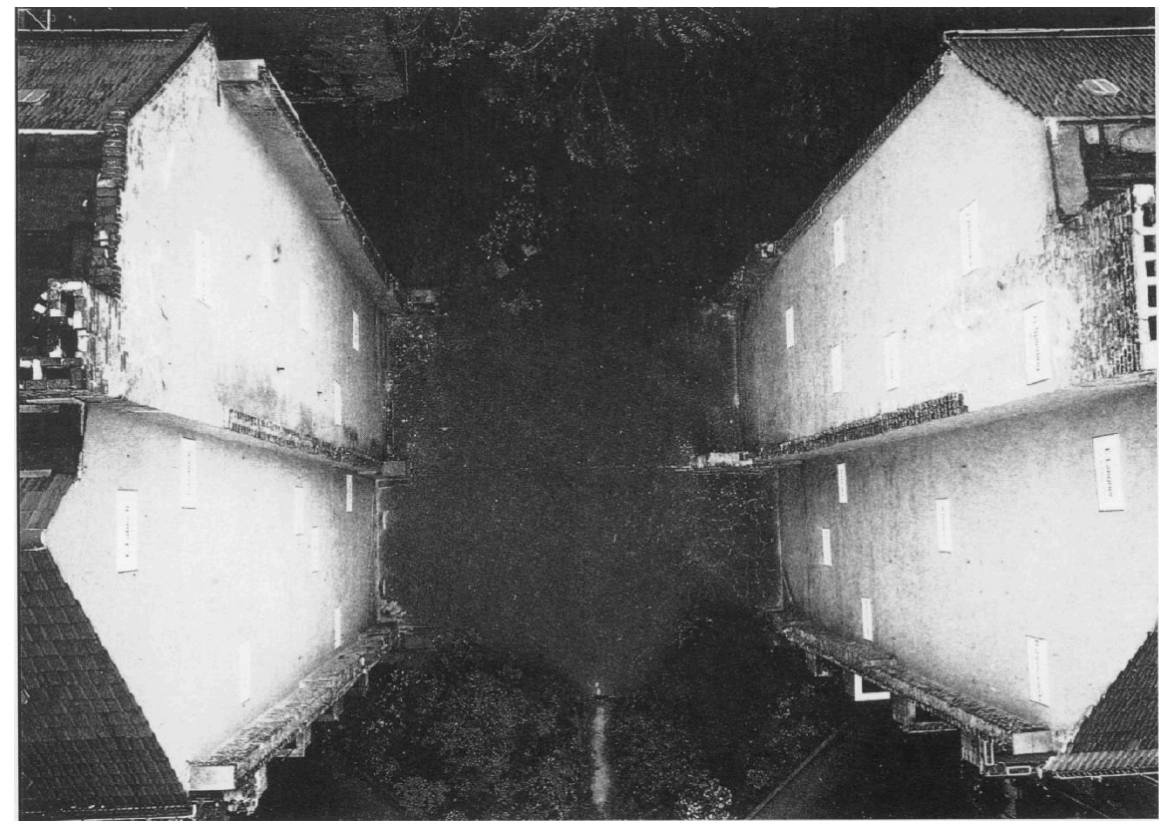

Figure 1. Boltanski, C. (1991). Missing House.

Christian Boltanski’s (1991) work often explores mourning, death (in individuals and groups), and memory through art installations to memorialize the lives of the dead. In his site-specific piece, The Missing House (1990), Boltanski uses an empty lot in East Berlin in between existing buildings where apartment 15/16 Grosse Hamburgerstrasse used to be before it was bombed in 
1945 during WWII (Solomon-Godeau, 1998, p. 3). Boltanski's installation consisted of a series of twelve black and white plaques mounted on the side walls of the buildings on each side of the vacant lot on different stories: listing family name, profession, and period of residency of each tenant who lived in the bombed apartments (Solomon-Godeau, 1998, p. 4). It highlights the absence and loss of the building and its Jewish tenants who occupied the building before the war, who were taken to concentration camps (Solomon-Godeau, 1998, p. 7). The empty lot acts as an index sign of loss, while symbolizing the after affects of war. By using historically accurate data, the piece brings forth the harsh reality of the past, making it stand in the present (SolomonGodeau, 1998, p. 7). The piece symbolizes the lives lost during the war, an erasure of the Jewish community. The embodied effect of the piece is one that creates a sense of loss through the space being used - specifically, the absence of the space. This effect creates an index sign of an invisible mirror, placing the viewer in the viewpoint of the people that are gone, in this case, the tenants of the previous space (Merleau Ponty, 1996, p. 129-130). The installation acts as an index sign of the absence of lives through the presence of the name plaques. 


\section{Felix Gonzalez Torres's Untitled (Portrait of Ross in L.A.) (1991)}

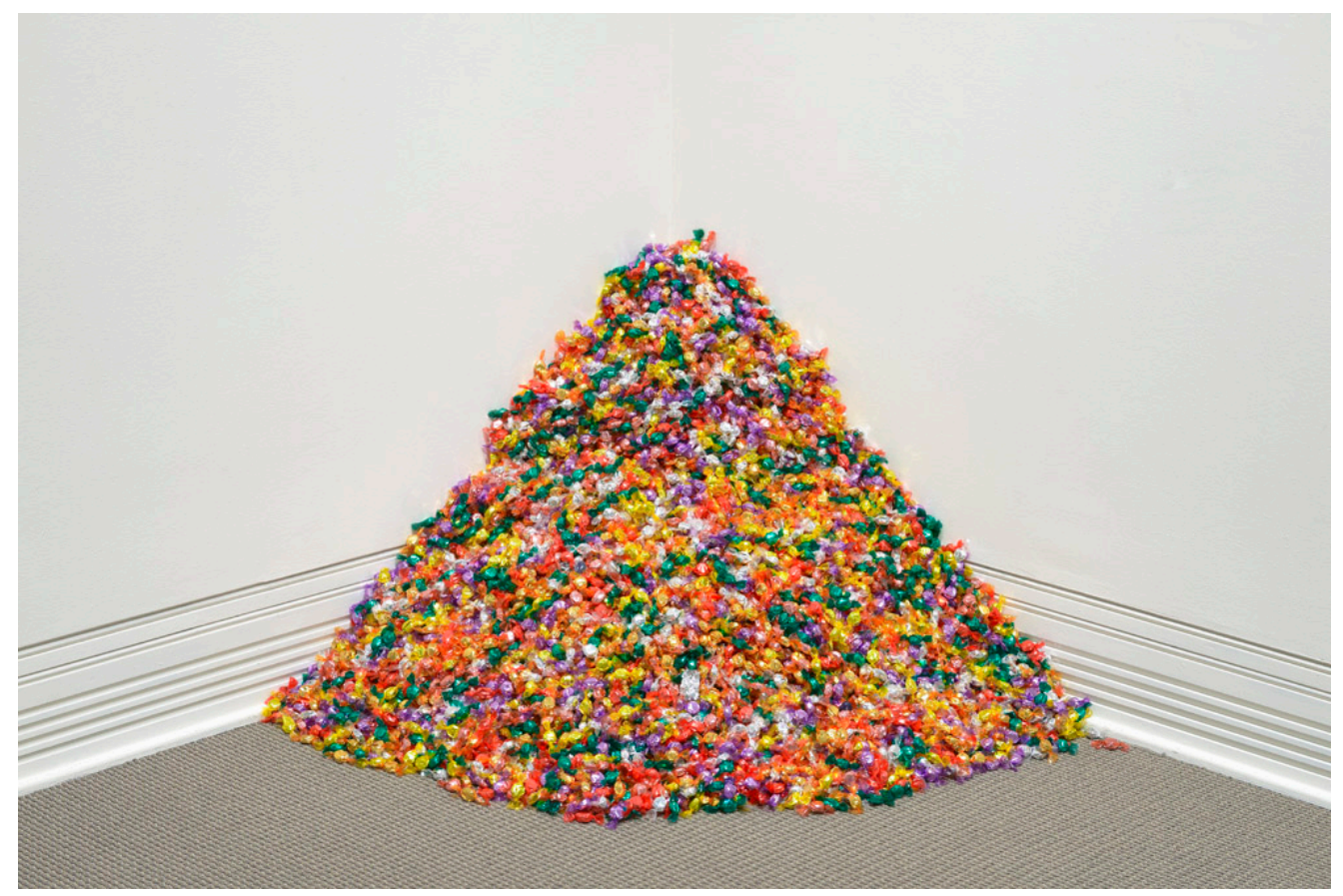

Figure 2. Gonzalez-Torres, F. (1991). "Untitled" (Portrait of Ross in L.A.). Candies individually wrapped in multicolored cellophane, endless supply. Overall dimensions vary.

Gonzalez-Torres's Untitled series (Portrait of Ross in L.A.) (1991), is an interactive installation piece where individually wrapped candies are placed in a corner of the room, and the viewer is invited to take, unwrap and eat the candy (The Art Story Contributors, 2018). After the candy is taken, the pile is replenished, which acts as a symbol of a cycle of life and death (The Art Story Contributors, 2018). The candy pile was constantly replenished to $175 \mathrm{lbs}$., the "ideal" weight of Felix's partner before he contracted HIV (The Art Story Contributors, 2018). A series of such works was created to represent different people by the different parameters of the installation: different weights, colours, or personal associations (The Art Story Contributors, 2018). This series of installations has become a symbol of the lives lost in the HIV/AIDS epidemic, previously seen as "gay cancer", when proper funding to advance treatment was not possible for 
years (The Art Story Contributors, 2018). The multi-coloured candies act as a symbol to signify the LGBTQ community. The installation exemplifies Gonzalez-Torres mourning his partner on an individualistic level, but also a mourning for the mass amounts of people affected by the HIV/AIDS epidemic.

\section{Bill Viola's The Passing (1991)}

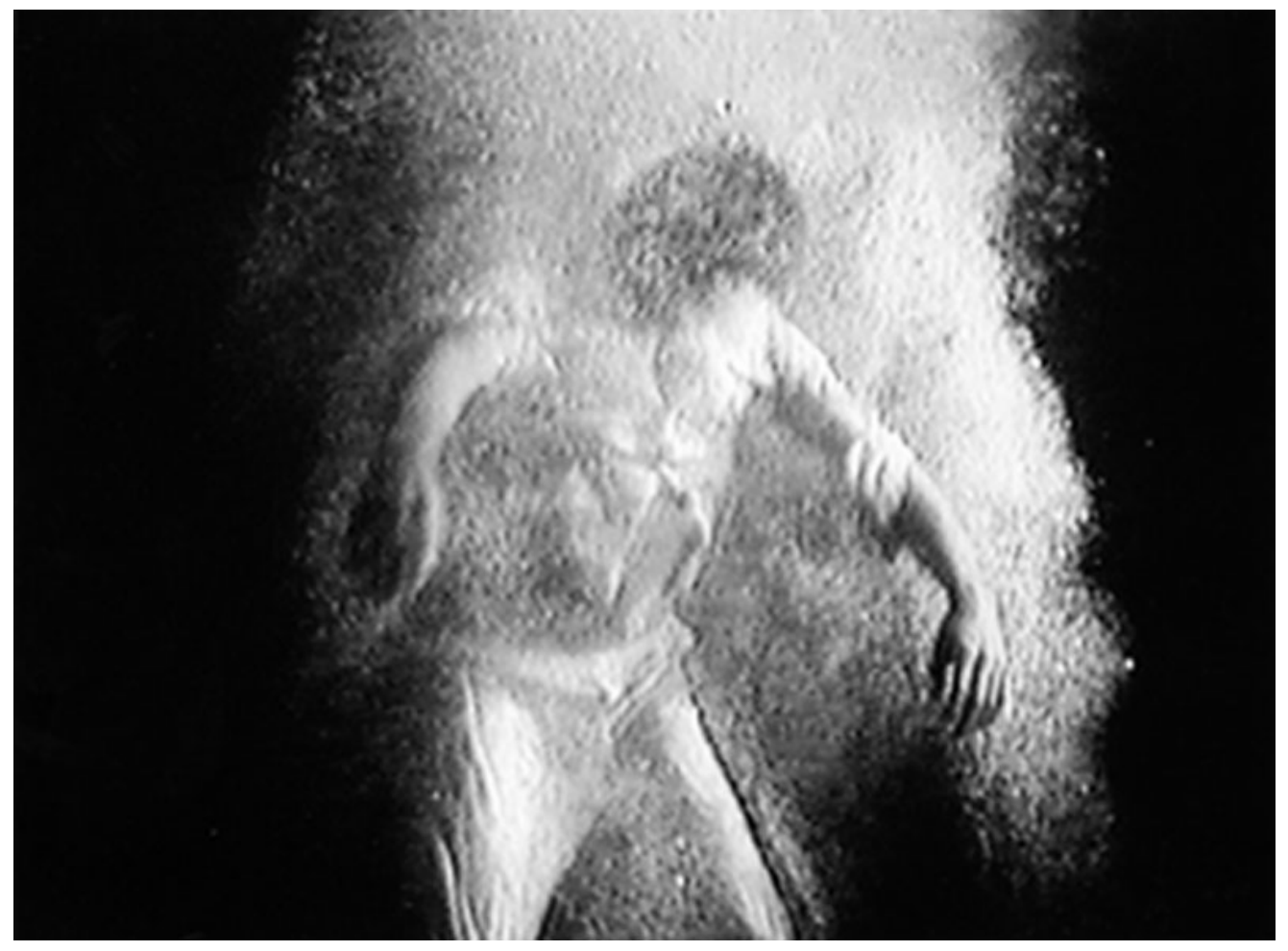

Figure 3. Viola, B. (1991). The Passing.

Viola's video installation, The Passing (1991), shows an image of a person almost drowning in water (Kuspit, 1993). The night sky begins the work, then moves to the figure, which then returns to the sky (Kuspit, 1993). Family milestones are then shown: the birth of Viola's son and the sickness of Viola's mother before her death (Kuspit, 1993). Viola often contrasts symbols within his work: life to death, sky to water, etc. He illustrates different states of being, often 
placing these states as transient moments, bringing them into focus and then swiftly changing them (Kuspit, 1993). Viola utilizes the medium of video by post-narrative sequencing, surreal textures, and post-montage splices to convey a radical state of consciousness that connects to personal sensation (Kuspit, 1993). The editing of the video brings forth notions of inner selfperception. The drowning aspect in Viola's work connotes anxieties of the disintegration of self, further emphasized by images of his dying mother. Viola's depiction of self being submerged in water is one that raises the question of why there is being (specifically human being) (Kuspit, 1993). A figure is submerged and appears drowning in water, which contrasts the image of a child within a womb, constructing the symbolism of life and death. The artist himself is mourning, and this translates through the symbols being used behind the work. For example, Viola often uses elements (air, water, fire, earth) to symbolize life and death. The viewer then interprets these symbols, although not perhaps completely consciously. But the perceptual experience that takes place allows for a phenomenological explication. The viewer extracts their own meaning from the piece, a unique experience for themselves.

\section{Itraru Sasaki's The Wind Phone (2016)}

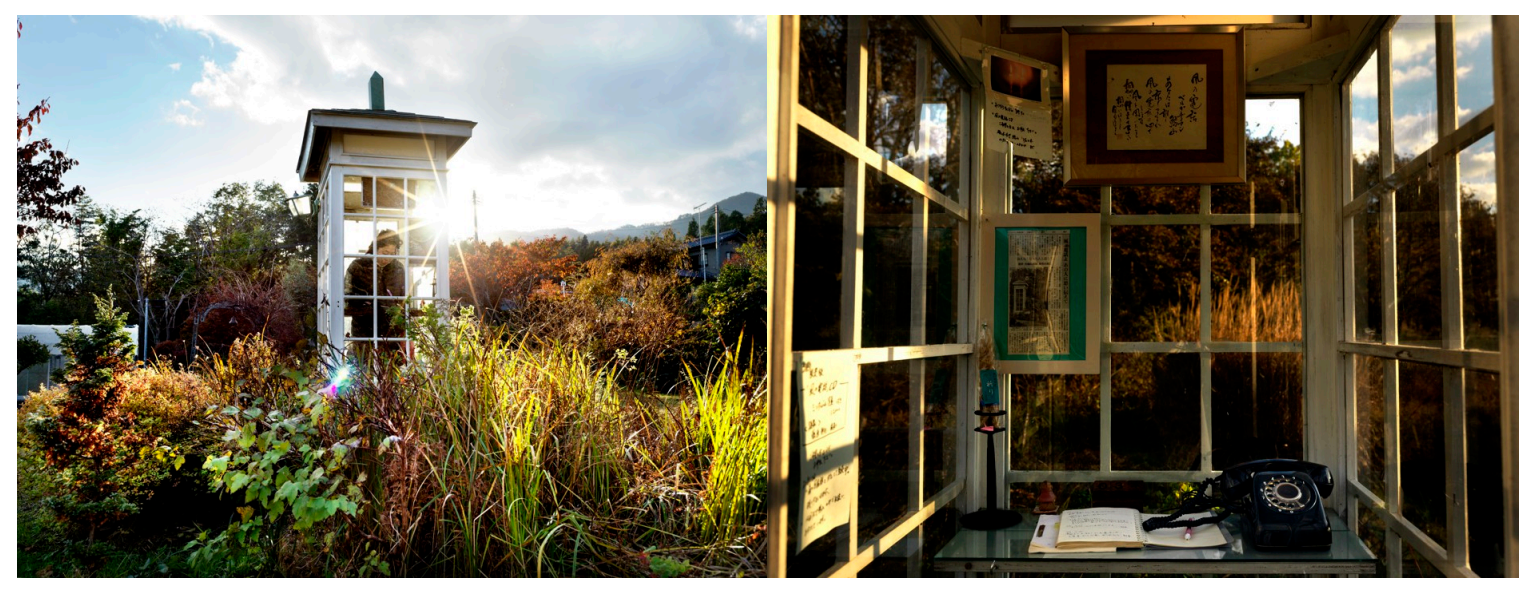

Figure 4. Wilson, A. M. (2016). Itaru Sasaki's Wind Phone. 
Itaru Sasaki's The Wind Phone is an interactive installation in Otsuchi Japan, where visitors can enter a phone booth to make calls to their deceased loved ones. The installation allows visitors to make phone calls to the dead, allowing them a connection with their deceased loved ones (Thisamericanlife.org, 2017). This installation is permanent, and has been visited by thousands of people from all over Japan, including people who have lost relatives during the tsunami and earthquake (Thisamericanlife.org, 2017). The mourners discuss various topics to their loved ones, from everyday activities and life updates, to messages such as "I miss you" and "I hope you are well" (CityLab, 2017). The visitors seek this particular phone booth due to its name, The Wind Phone, as it relays messages to the wind (CityLab, 2017). Visitors have expressed that their thoughts cannot be articulated through a regular phone line, and they seek out the Wind Phone so their thoughts can be "carried on the wind" (CityLab, 2017). The word "Wind" attached to phone acts as a symbol of communication to another spiritual realm. The phone can universally be seen as a symbol of communication, and in this case, a chance to communicate with the dead. The phone booth can be seen as an embodied experience by providing stimuli to the mourner, as an object of personal consciousness, and connecting the mourner to their deceased loved ones (Husserl, 1913, p. 198-199). The enclosed structure of the telephone booth allows for the mourner to move from the outside space into a private space. When they enter the space, images or pictures of the deceased loved ones can solely exist within the mind of the mourner. I would argue that the title of the space creates a commemorative grieving space, allowing the viewer to be comfortable enough to grieve as the symbol of the phone is recognizable, while the unfamiliarity of the space of where the phone booth is located (on top of a hill that they must travel to) changes their perception of how the calls are being reached. The 
installation itself does not use symbols or signs of death but conveys an aura of un-canniness based on space and common objects. This allows the mourner to interpret the installation based on their own personal mourning experience.

\section{Taryn Simon's An Occupation of Loss (2016)}

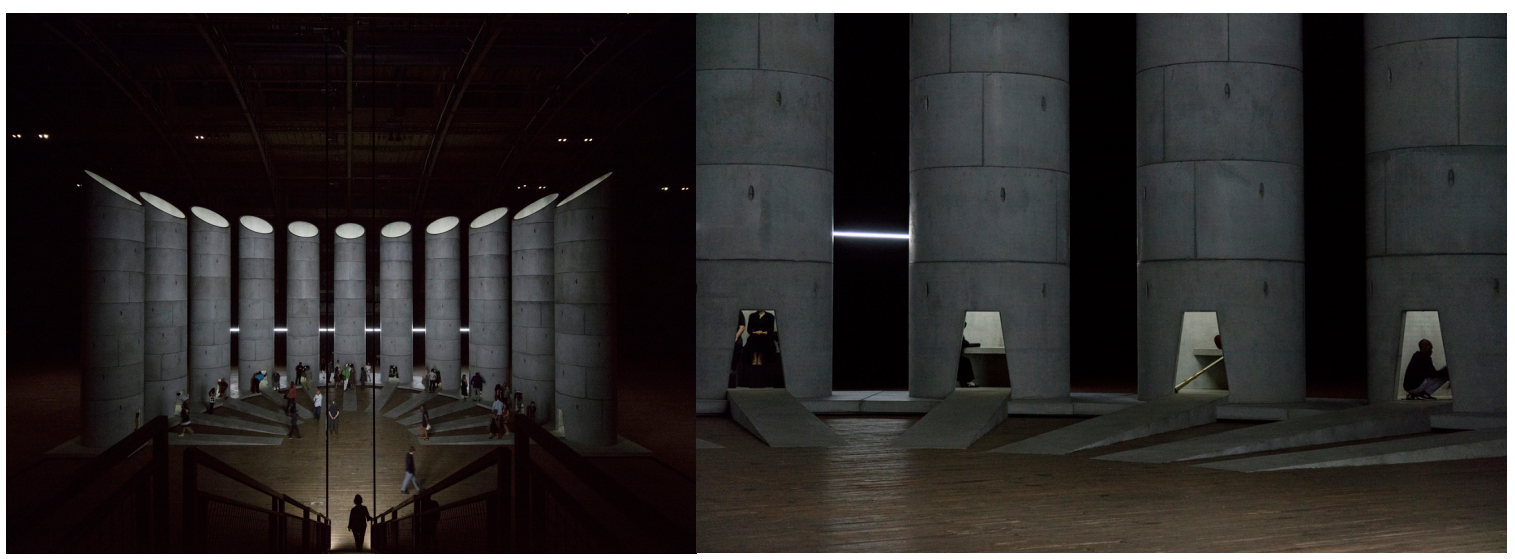

Figure 5. Kubota, N. (2016). Taryn Simon's An Occupation of Loss.

Simon's An Occupation of Loss (2016) is a performance and interactive installation piece that consists of eleven narrow raw concrete towers with arched open entrances standing within a semi-circle space that viewers can enter (Witt, 2017). The signs and symbols within the installation can resemble large organ pipes, missiles on a missile platform, or grain silos (Russeth, 2016). Thirty professional mourners from fifteen different countries were hired to speak, sing, pray, play music and cry in various languages (Russeth, 2016). Simon purposefully abstracts the objects of mourning, allowing the viewer to make their own associations with the experience (Witt, 2017). Witt (2017), a writer for the New Yorker describes the mood as "somber, even frightening." She shared her realization of this experience saying that "mourning, I understood then, is a distraction from loss; after bodies are buried and ceremonies end, there 
only remains an empty and relentless silence" (Witt, 2017). The space created by the installation is similar to the phenomenological idea of the person as a center of a surrounding world (Husserl, 1913, p. 195). In this case, the eleven pillar/inner mourning spaces act as eleven separate surrounding worlds, whereas the entirety of the installation acts as a separate surrounding world, encompassing many different kinds of worlds together. The installation creates its own universe of mourning. The viewers enter different worlds of the professional mourners, placing them in what they might understand to be that mourner's "surrounding world" (Husserl, 1913, p. 195). The different languages of the mourners signify these worlds, sometimes colliding with the other mourners' worlds. The effect of this allows the viewer to have their own unique embodied experience, as they try and make sense of these worlds of sober tones, with the possibility of understanding a language, or possibly not. The installation demonstrates the universal nature of mourning.

\section{Conclusion}

What is common among all of these artists is that they try to represent their mourning process, and/or allow the viewer to view different perspectives of the mourning process. Each installation uses signs and symbols that help create an embodied experience for the viewer. Common themes explored between the art installations are absence represented by presence (or loss), and created "worlds" of mourners; aesthetic motifs exploring the elements and enclosures.

Loss, or absence seen through presence is represented differently within a few of these interactive art installations, along with my interactive art installation, A Constant Revise (2014). Christian Boltanski’s Missing House (1991), and A Constant Revise (2014) use an indexical sign of absence seen through presence. A sign of loss is then created in both installations. Space is 
used to emphasize the motif of loss in different ways. Missing House (1991) uses the physical loss of a space as an iconic sign of loss, and uses the name plaques of the Jewish tenants as a symbol of presence to emphasize the loss of their lives. A Constant Revise (2014) uses the presence of the objects of a deceased loved one as an indexical sign of their absence. The installation also shows an iconic sign of their deceased loved one through video, representing their absence through emphasizing their presence by pausing, and repeating their image. Gonzalez-Torres's Untitled series (Portrait of Ross in L.A.) (1991) also symbolizes absence through presence from an unknown object, candy. The amount of candies that make up the weight of Gonzalez-Torre's loved one symbolizes the loss through the presence of the physical material. The symbols and signs behind the installations help create an embodied effect for the viewer.

The elements are also explored as symbols within two installations. Bill Viola's, The Passing (1991), uses the element water as a symbol for birth/death through the experiences of drowning and being born. Itaru Sasaki's, The Wind Phone (2016), uses its name as a symbol for communication to another spiritual realm.

The use of "worlds" of the mourner as a theme is seen in An Occupation of Loss (2016) and $A$ Constant Revise (2014). The participant experiences the "world" of the mourner, which is often unique and personalized to that mourner's story or history. The participant is able to gain a unique embodied experience by perceiving the mourner's world.

The aesthetic motif of enclosures is seen in some form within all interactive art installations. We see an enclosure within Missing House (1991), as the empty lot between two apartment complexes, surrounding the viewer on two sides. An enclosure is also seen more subtly in Untitled series (Portrait of Ross in L.A.), as the pieces of candy are piled within a 
corner of a space (or the walls are seeping in to enclose the symbolized body). The Passing (1991) shows an enclosure as the mother's womb, as well as images of a figure drowning, and water enclosing the viewer. The Wind Phone (2016) uses the enclosure of a telephone booth to allow for a private space for the mourner to conceal themselves in when making phone calls to their deceased loved ones. Taryn Simon's An Occupation of Loss (2016) uses eleven towers as eleven enclosures of the different "worlds" of the mourners, as well as the towers within a semicircle sphere to enclose the installation as a "world" of mourning. A Constant Revise (2014) uses the enclosure of a semi-circle curtain to enclose the viewer into the "world" of the author. The enclosure motif acts as a symbol of grief as a private space for the mourner. The enclosures tend to utilize the space, often to emphasize the theme of loss or grief. This often creates an embodied experience for the mourner.

Christian Boltanski (1990), Felix Gonzalez Torres (1991), Bill Viola (1991), Itaru Sasaki (2016) and Taryn Simon (2016) prompt the viewer to facilitate discussion on topics of mourning. The symbols and signs within the installations trigger an embodied effect of the interactive installations. The viewer is able to take away a unique experience based on their perception of the work, such as a shift in perspective. Gaps in this field of art installations are the connection between the artists' works of mourning and the psychological benefits of their art installations on mourners. Further research needs to be done on the individual psychological benefits of these artists' works. 


\section{References}

Boltanski, C. (1991). Missing House. [Photograph]. Retrieved from http://www.jstor.org/stable/1360612.

CityLab. (2017). The Phone Booth for Japanese Mourners. [online] Available at: https://www.citylab.com/life/2017/01/otsuchi-wind-phone-japanese-mourners/512681/ [Accessed 6 Oct. 2017]

Glynn, R. Foreword. In Fox, M. (Ed.). (2016). Interactive architecture : adaptive world. Princeton Architectural Press, New York. 7-14.

Gonzalez-Torres, F. (1991). "Untitled" (Portrait of Ross in L.A.). [Photograph] Retrieved from https://www.artpractical.com/feature/citizenship-the-body-and-the-ethics-of-exposure/

Husserl, E. (1913). The Person as Center of a Surrounding World. Ideas II. Studies in the Phenomenology of Constitution. 194-199.

Kubota, N. (2016). Taryn Simon's An Occupation of Loss. [Photograph]. Retrived from http://www.artnews.com/2016/09/14/beautiful-mourning-taryn-simon-stages-a-movingand-discomfiting-performance-at-the-park-avenue-armory/

Kuspit, D. (1993, September). Bill Viola: The Passing. Artforum International, 32(1), 144+. Retrieved from http://link.galegroup.com.ezproxy.lib.ryerson.ca/apps/doc/A14580125/ $\mathrm{AONE} ? \mathrm{u}=\mathrm{rpu} \_$main $\& \mathrm{sid}=\mathrm{AONE} \& \mathrm{xid}=82719 \mathrm{cc} 2$

Lévinas, E. (1969). Totality and infinity: An essay on exteriority. (Lingis, A., Trans.), 220-254. Pittsburgh, Pennsylvania: Duquesne University Press.

Merleau-Ponty, M. (1996). Eye and Mind. In The Merleau-Ponty aesthetics reader: Philosophy and painting (G. A. Johnson, Ed.), (pp. 121-164). Evanston, IL: Northwestern University Press.

Russeth, A. (2016, September 14). Beautiful Mourning: Taryn Simon Stages a Moving and Discomfiting Performance at the Park Avenue Armory. ArtNews.Com. Retrieved from http://www.artnews.com/2016/09/14/beautiful-mourning-taryn-simon-stages-amoving-and-discomfiting-performance-at-the-park-avenue-armory/

Simon, T. (2018). Occupation of Loss. Retrieved June 7, 2018, from http://tarynsimon.com/works/occupation_of_loss/\#1 
Solomon-Godeau, A. (1998). Mourning or Melancholia: Christian Boltanski's "Missing House". Oxford Art Journal, 21(2), 3-20.

Tate. (n.d.). Installation art - Art Term. Retrieved from https://www.tate.org.uk/art/artterms/i/installation-art.

The Art Story Contributors. (2018). Felix Gonzalez-Torres Artist Overview and Analysis. TheArtStory.Org. Retrieved June, 2018, from http://www.theartstory.org/artist-gonzaleztorres-felix-artworks.htm\#pnt_6

Thisamericanlife.org. (2017). Transcript | This American Life [online] Available at: https://www.thisamericanlife.org/radio-archives/episode/597/transcript [Accessed 3 Oct. 2017].

Urbanowicz, K., \& Nyka, L. (2016). Media Architecture and Interactive Art Installations Stimulating Human Involvement and Activities in Public Spaces. CBU International Conference Proceedings, 4. 591.

Viola, B. (1991). The Passing. [Photograph]. Retrieved from http://diariesmemoriesmetaphor.blogspot.com/2010/06/passing-by-bill-viola.html

Wilson, A. M. (2016). Itaru Sasaki's Wind Phone. [Photograph]. Retrieved from https://www.citylab.com/life/2017/01/otsuchi-wind-phone-japanese-mourners/512681/

Witt, E. (2017, July 10). Taryn Simon's Varieties of Mourning. New Yorker. Retrieved from https://www.newyorker.com/culture/culture-desk/taryn-simons-varieties-ofmourning?mbid=rss 


\section{CHAPTER 3}

\section{A Constant Revise}

Introduction

Our memories construct, to a great extent, our grasp of another person's identity. The identity of the other changes when new memories of them are formed or old ones are represented or recreated. If no new memories of a person are produced, the old ones are reconfigured, or forgotten. How we ourselves see and interpret our memories of the people who have passed away can help us reflect on our own relationships with them, and rationalize how we perceive ourselves. Throughout the final year of my undergraduate degree, I explored the concepts of death, memory and identity through a semiotic lens. Although collective memory of loss has influenced my work, the main focus of my research is the individual experience of mourning. I asked, "How does time, the loss of memory and change in perception alter for us the identity and knowledge of a departed loved one?" and, "How can a surrounding space and the medium of video be utilized to recreate for the viewer the personal memories and experiences of the author?" I addressed this question by creating an interactive installation entitled $A$ Constant Revise. My main motivation for this work was to help myself cope with the loss of my father, and to use exploration and experimentation as forms of meaning-making in self-therapy. The first part of this chapter will describe my design process of my interactive installation as I explored and developed my research question, and the research that affected my process. Its second part will be a reflection on my work through a phenomenological and sociopsychological lens, my personal meaning-making process more in-depth, and on the ways this personal piece of work is relevant and relatable to others currently in mourning. 
Part I

My Design Process of the Interactive Installation A Constant Revise (2014)

I explored the importance of time in relation to memory, the creation of visual voids representing emotional voids, and the visualization of the persistent sense of absence through the use of emphasized presence. My goal was to create a sensitive experience for the viewer, and I did so through light exploration, space construction and personal family imagery.

I visited the 9/11 war memorial in New York City to do on-site research on my topic. It was the experience of being at the memorial that made me question how we remember the dead. What is the importance of the experience of remembering our past loved ones? How do we design these personal experiences?

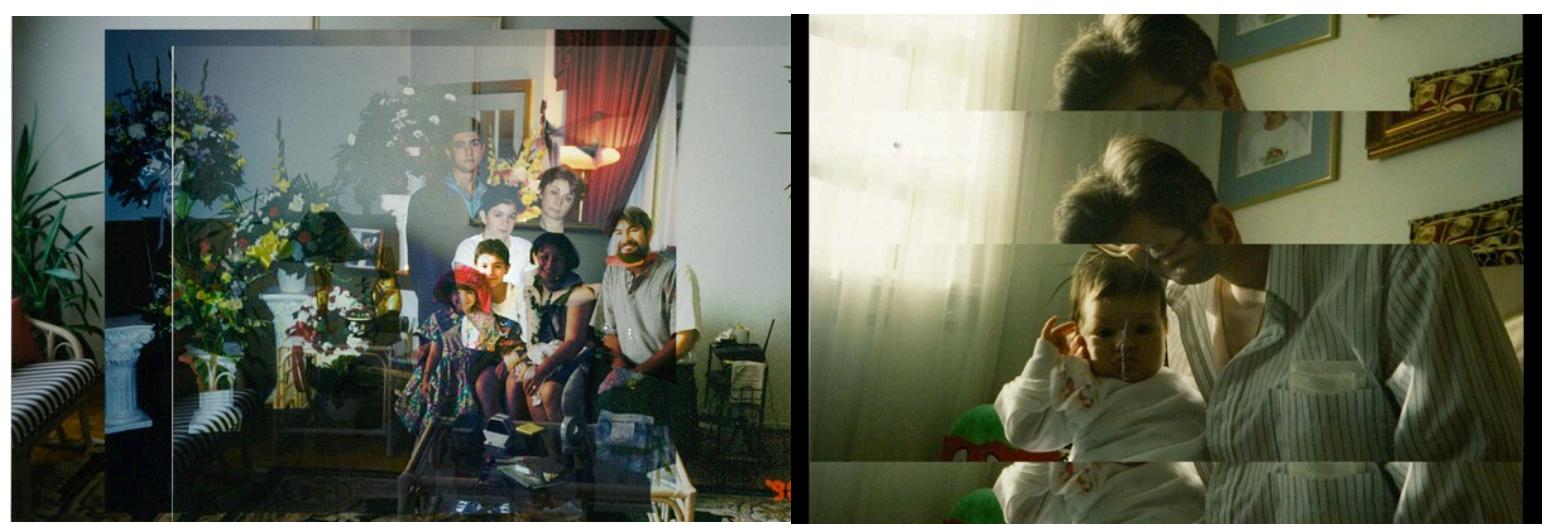

Figure 1. Overlapping of time periods.

Figure 2. Folded photograph.

After reading Deleuze's (1991) The Fold, I started thinking how to further my exploration and reflect on possible ways to construct different visual images to visualize memory through representing different layers of meaning. My exploration with family imagery focused on combining different time periods or taking away physical material to represent memory in 
diverse ways. I wanted to experiment with different visuals to symbolize the identity of my father fading and changing from memory. This brought me to multiply different time periods over one another, as well as show the passage of time through gesture (see Figure 1). For example, using different images of my father's funeral allowed me to represent death through the visual signifiers of death (e.g. wearing of black, tombstone, sad expressions, gathering around the grave). I used the idea of the fold for my photographs, as an immediate transition that unravels more information (see Figure 2). The exploration also took form through colour interpretation, as a loss of colour that meant a loss of clarity (see Figure 3). Another experiment was to photocopy the same image of a person over and over again to show a slow degradation of the image and memory, making the person in the photograph unrecognizable (see Figure 4). These explorations would later develop through the form of video and would later inspire my final product.

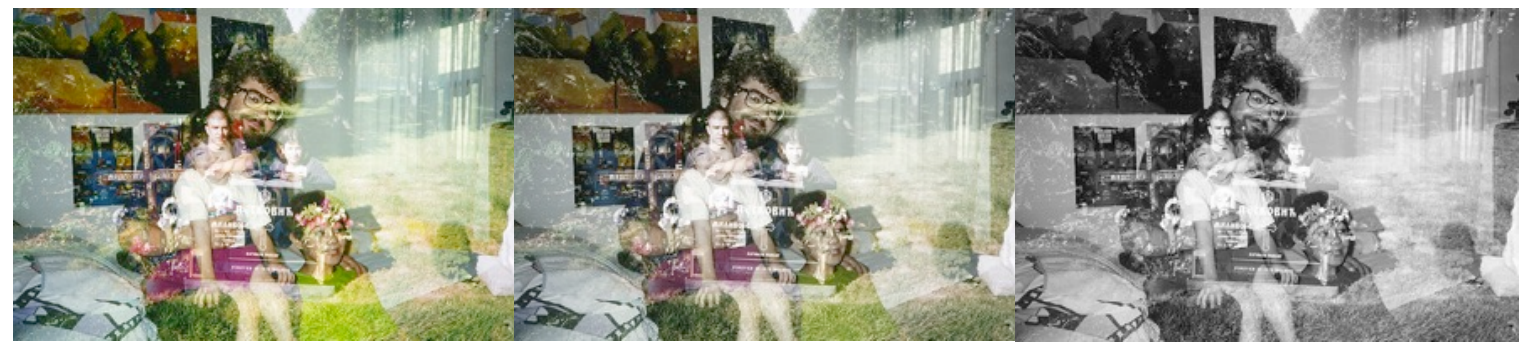

Figure 3. Desaturating images. 


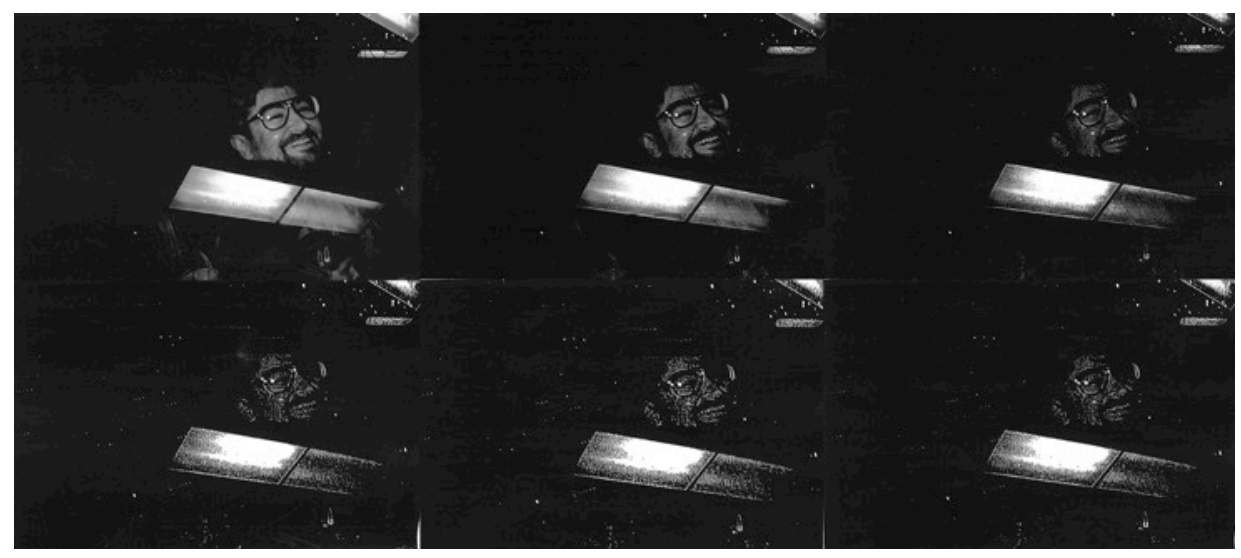

Figure 4. Photocopied Image, loss of clarity.

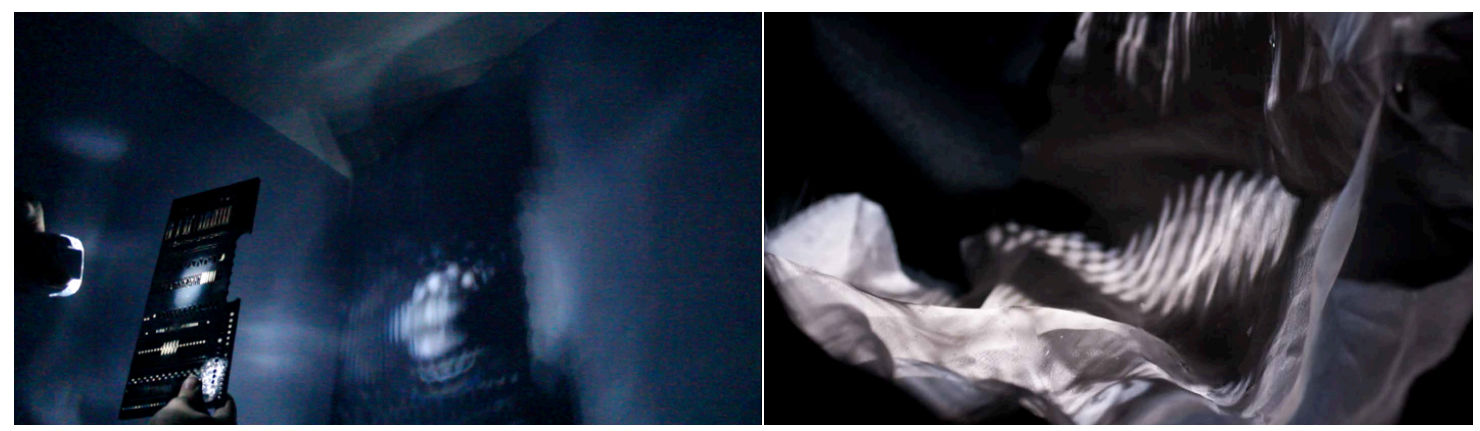

Figure 5. Light explorations in pattern. Figure 6. Light explorations in pattern and environment.

I attempted to represent memory through light experiments by utilizing the motion of time. These experiments were focused on pattern, movement, time, and transformation. I created patterns to symbolize the connection of people using shapes, through the use of intersecting and overlapping. I then projected light through these laser cut patterns of acrylic material (See Figure 5). I attempted to create environments for these light patterns to live in and out of paper, and then cloth (See Figure 6). The further I moved the light away from the shape base on the acrylic, the more blurred and unrecognizable the forms were. This signified memory, as the further away in time an event happened, the harder it is to remember details and facts concerning the event. Visibility as a means of knowing was seen as a process of understanding the world, for example, 
the visual properties of objects that were investigated in seventeenth century still life (Hallam and Hockey, 2001, p. 63). How visible and recognizable a pattern or object is in space is dependent on the lighting on the object and the space, and the distance between the light and object. I considered light as a tool to symbolize clarity. My exploration of clarity and shape/image led me to experiment with the focus on camera lenses when recording video, and how this pertains to the importance of visibility in relation to representing memory. My explorations with light and space, material and form, and personal family imagery then led me to further questioning: what does the presence of shadow bring? How does space interact with the viewer? What is the significance of space for memory and the experience of another's' death? How does sound affect space and extend the effects of memory? How does personal experience relate to other people and community in general? These questions were kept in mind when later explorations were done.

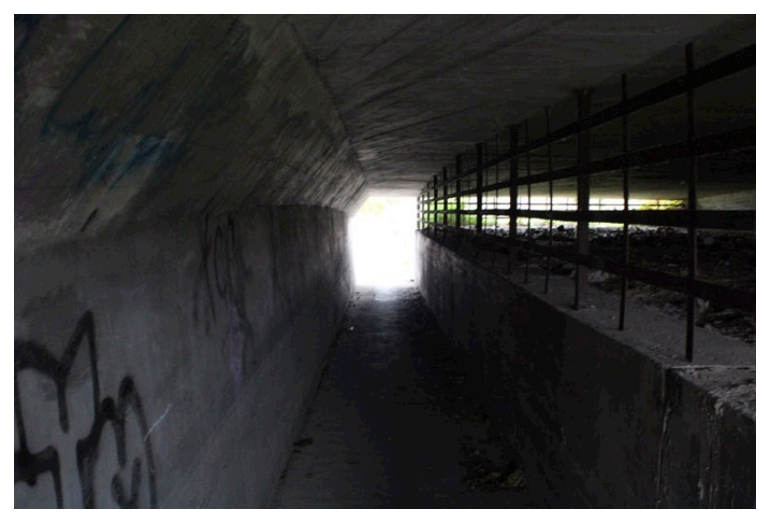

Figure 7. Tunnel.

Questions about the actual place of the installation — whether in a private or a public space-arose when I decided to explore location. I photographed different sites and areas around Toronto searching for spaces and places that inspire personal memory. For a period, I was 
focused on a small tunnel near my neighbourhood (See Figure 7). A tunnel represents the transition between two environments. It represents the in-between of being stuck, confused and lost. It represents the passage of life to death. The aspect of displaying work off-site for my installation became difficult due to weather conditions and how complicated the project had become. What became a critical question was whether I wanted to represent memories in relation to home or render memories in relation to loss? I soon realized that representing all the emotions and memories that can come over a person after the death of a loved one, and putting it into one installation, would take longer than a year to theorize and create.

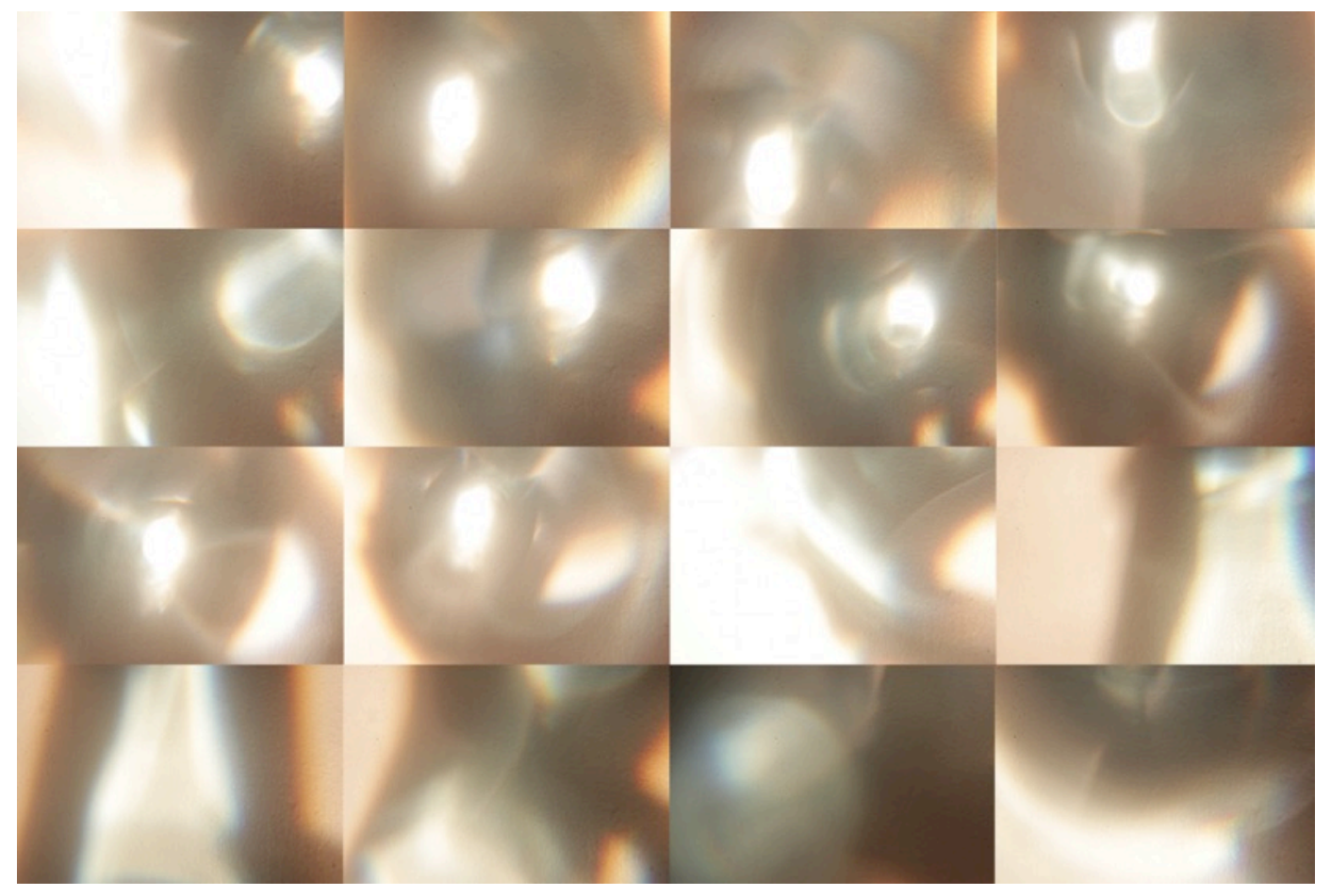

Figure 8. Folding Light.

My explorations of light and shadow led me to experiment with an old projector. With this, I started switching between opaque and different cut pieces of glass to move light in 
different directions (See Figure 8). When I began videotaping these experiments, I started folding the light by moving the glass with my hand in different angles. After watching Enter The Void (2009), I was inspired to mirror my explorations to create abstract representations of an emotional void. Enter the Void (2009) also took theory from the Tibetan Book of the Dead (2007), and represented these theories visually through light and shadow vacuums. I was also influenced by artist Lilanne Lijn, whose work emphasizes light as a passage to another cosmic plane when experiencing the death of a material body (Lijn, L., \& Mellor, D, 2005, p. 83). I tried to represent passages in a person's life through the movement of shadow as a representation of void (See Figure $9.1 \& 9.2$ ). Shadows were created by how I directed and moved light within a glass. The emergence of light from darkness and vice versa signifies the flow of time (Hallam and Hockey, 51). Although I perceived my intention as clear, my professors found my imagery to be too abstract for the content. My greatest difficulty was to try to combine my separate light explorations with family imagery and space creation. I later realized that my projected video of family archives was an in-between stage of my investigations.

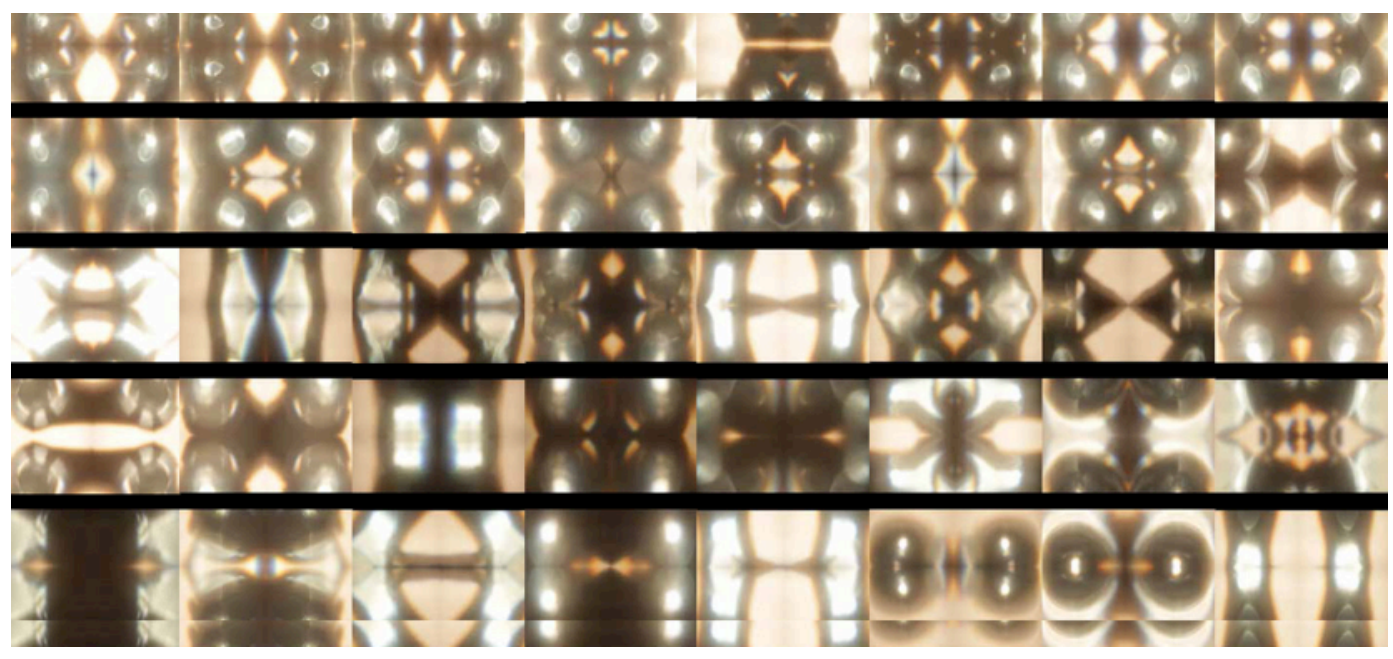

Figure 9.1. Visual Voids. 


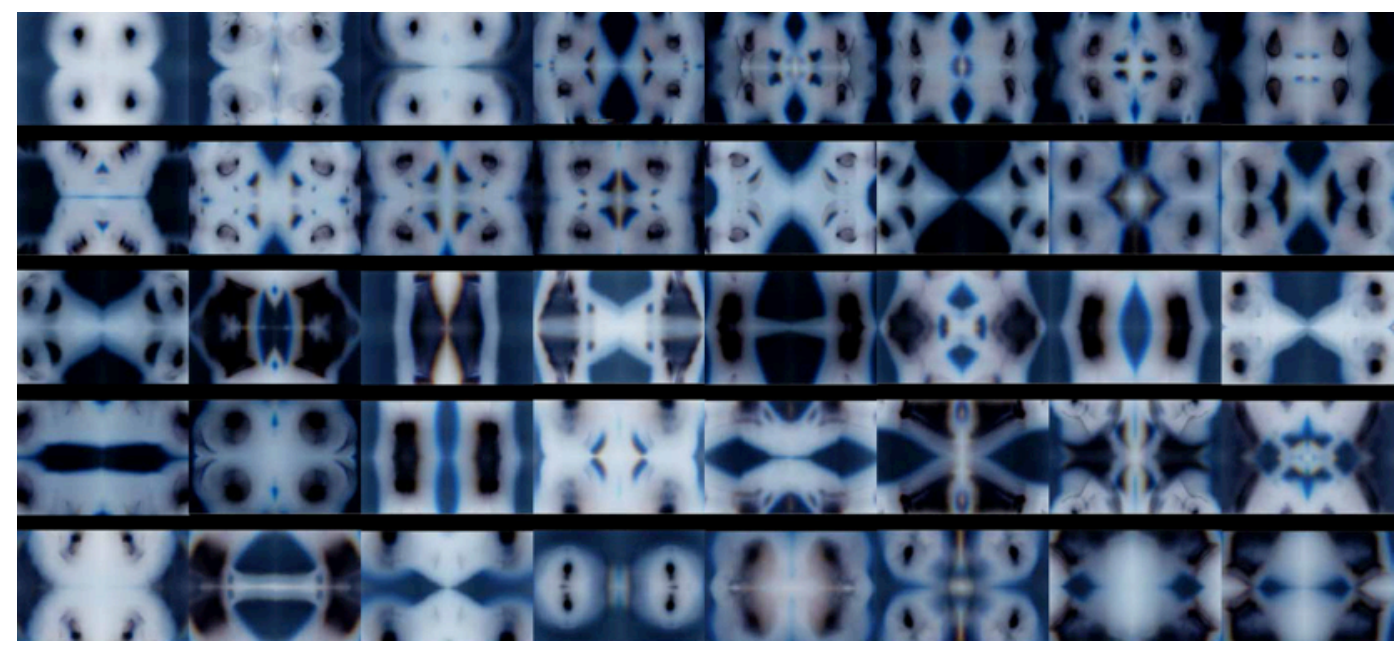

Figure 9.2. Visual Voids.

Manipulating personal family photographs led me to start experimenting with manipulating archived family home videos. Although I had this in mind during the first semester, I tried to migrate the video by upgrading the source material from VHS to DVD. However, I gave up on this prospect and decided to re-film my home videos, reinterpreting the media through a camera. By using a macro lens, I experimented with the lens' focus, which manipulated the medium, making it unclear of the subject matter when out of focus (See Figure 10). What I was doing was translating this documentation through the means of my perception, my own interpretation. Lotz (2004) describes this process:

If the process of mourning as that what "institutes my relation to myself and constitutes the egoity of the ego" is inevitably connected with the process of recollection, and if recollection is based on absence, then mourning/recollection must fail and with its failure constitute a being-in-itself within itself. Consciousness, in other words, is always mourning and melancholia at the same time, since something is fundamentally lost, 
where recollection is just the visible side. Put differently, recollection tries to recollect what is unable to be recollected. Something that cannot be recollected (absolute past) cannot be represented. Something that cannot be represented does not become subjective and remains foreign. This irreducible otherness is what Derrida has in mind when he claims that mourning is possible, only on the basis of a failure of mourning (p. 137).

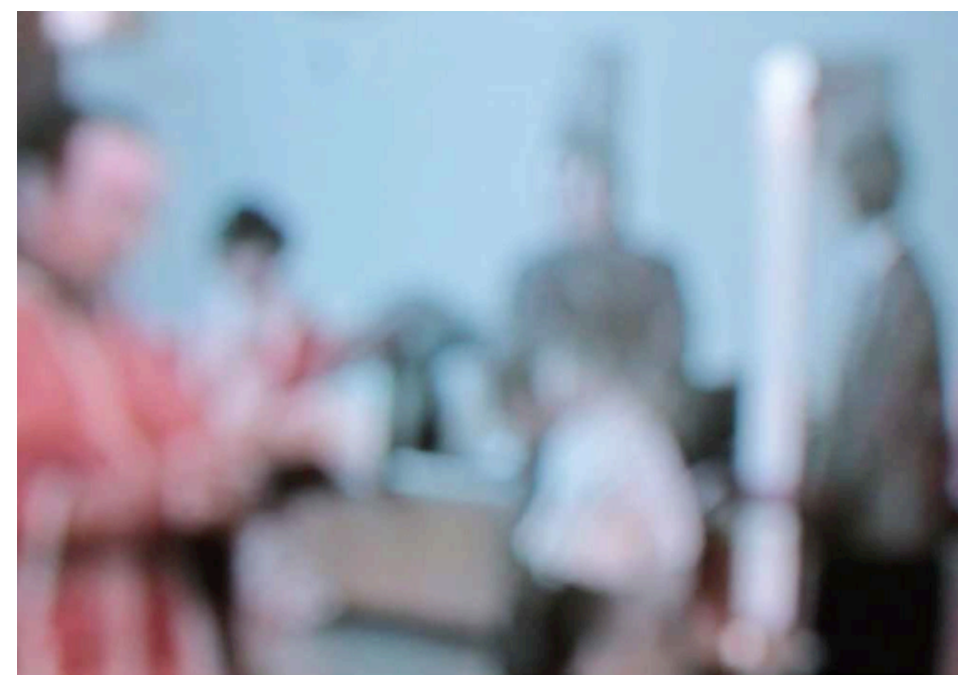

Figure 10. Unfocused scene.

Here, my recollection is the manipulation of the archived footage, which has already been documented by another observer through their lens. I was trying to recollect my memory of the archived footage, by showing how I was processing my memory by pausing, repeating and silencing clips. I cannot remember my own perspective of the memory within the footage, so I fail to recollect a "true memory", and only recollect an interpretation of the past, as the absolute past cannot be represented. I questioned this truth, as it is no longer true. This same method also created a questioning of the medium due to the time specificity of when the footage occurred. 
This became my response to my thesis question as it visualizes my memory, my own interpretation of what was documented and creates it into an experience for the viewer.

The VHS recorder also represents certain generations that have been brought to know the system in their household. A culture's view of their reality is reflected through the artistic forms of that time period (Eco, 1989, p.13). My generation was growing up between 1980s and 1990s, at the start of the digital age, when the VHS recorder was common for most homes. These tools become infused within our lives so much that they become a part of our memory, through subject matter and sometimes even the aesthetic form. These recordings are being projected onto a screen, which I would suggest is not only a screen in representation of memory, but also our connection to the digital screen. I will talk more about the connotations of the screen later on.

I decided on the same archive clip to be used for the beginning and end of my video, yet rewound and silent at the beginning, then full sound and regular speed at the end. I wanted this same footage as the starting point and end point as it was the only clip of just me and my father together. The beginning structure referencing the end and vice versa was inspired by the film Sans Soleil (1983). The aspect of allowing the film to be seen as a type of loop was a symbolic representation of life and death. I felt the need for the beginning to be muted, rewound and paused to give a sense of confusion as well as be slightly concerning. The muting signifies processing memory. The rewinding/fast-forwarding signifies someone going through this memory suggesting that someone else is in control of it, as if they are thinking and overanalyzing it. I used pausing within the video for contemplation about what exactly is happening in this memory, and why specifically is the person being highlighted. This clip also gets reinterpreted in two other parts of the film, and acts as a type of flashback or reference, breaking up what is currently being displayed. The same clip gets referenced repeatedly throughout the 
film, and is reexamined at the end. This narration technique is similar to that of the films Trance (2013) and Memento (2005), where clips at the beginning of the films are often viewed in a different perspective or time period later in the film.

I was at a loss as to how to structure the narrative of my video after deciding upon the first and last clip. After some contemplation and test videos, I created a type of structure that uses repetition to suggest absence through presence. This was done by overly emphasizing my father's presence by pausing video clips that he was in, and then moving to clips without him. I created three different occasions where focus is upon my father by using repetition of slow motion clips. This gave an eerie effect, and prompted the viewer to question the attention brought to my father's figure. Jung (1968) writes, "sometimes, it is not a dream but some very impressive and unforgettable real event that like a prophecy, anticipates the future in symbolic form" (p. 164). This repetition of my father's figure creates an emphasis on him, and questions why there is a prominence on him. The two major occurrences of focusing and un-focusing happen at the beginning and end of the film (See Figure 11). These clips question the notion of what is real, and challenges the time frame of when they are happening, is it created or reinterpreted. This structuring also suggests the film is going in and out of memory. 


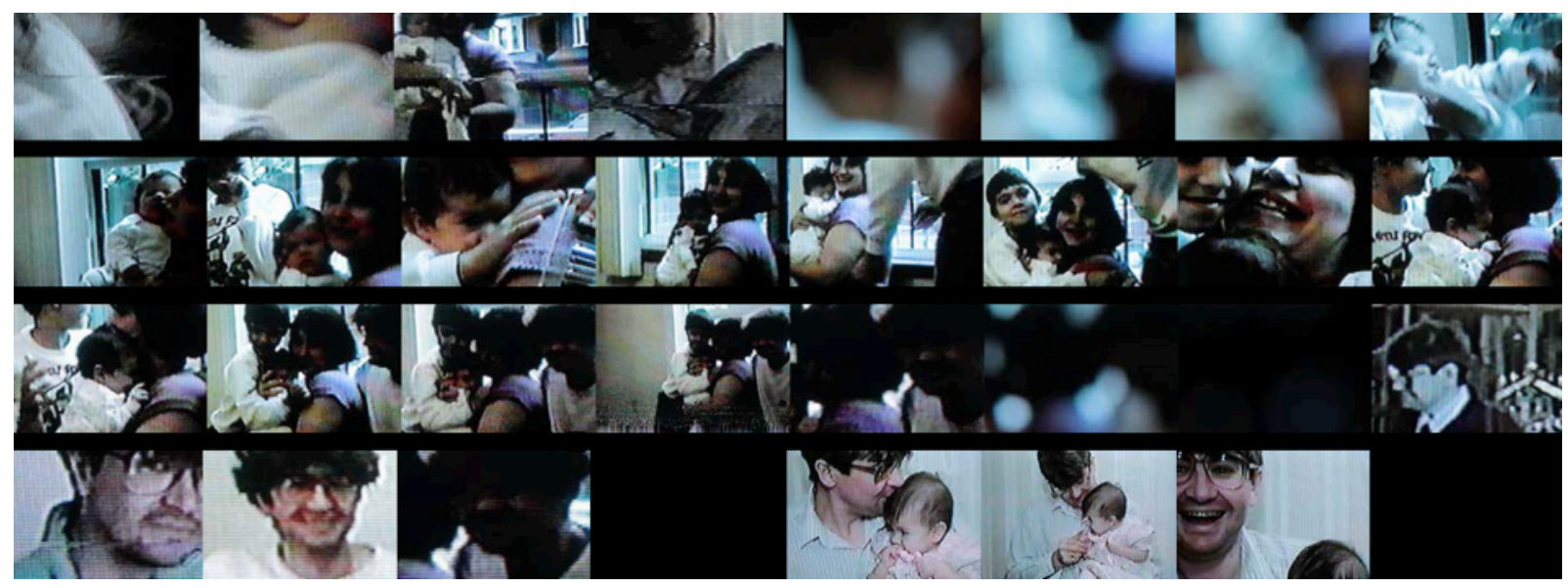

Figure 11. Two minutes of video sequence.

The church scene gives reference to life and death, ritual and ceremony. Even though the scene is not one of a funeral but a baptism, it is a setting of culture. The chanting of passages in old Serbian Orthodox give a surreal feeling to those who cannot understand the old dialect. It is a transitional point from various aspects of life.

The addition of voiceover was constantly in question for my work. After hearing $A$ Long River by Janet Cardiff (2001), which led the viewer around a space with only sound, it left me feeling as though voice added another layer of depth for my topic. However, after putting this in action, the narrative of my memory left me feeling vulnerable and confused. I believe I only chose to use my narration for the additional purpose of being less abstract and clearer. But the experience of the video when going through the footage felt weaker. After some reflection, I realized that the voiceover was not essential, as I did not need the viewer's approval. I was also trying to place the viewer in my perspective for the film, which rarely had me narrating to myself my own memories. I wanted the confusion of memories overlapping to be apparent, and so I vetoed the accompaniment of my voice for the video. 
Sound then became more difficult to integrate within my video. I decided upon recording the medium itself, sounds of rewinding a tape, fast-forwarding a tape, pausing a tape, and playing a tape. These sounds were mixed with clips from the actual VHS footage, clips that abstracted my father's voice, or clips that were reminiscent of a certain ritual (such as the chanting from the orthodox church scene).

What I found was more crucial to the sound of my film was silence. Knowing when exactly to break up noise to complete silence allowed more emphasis and focus on my father or the situation itself.

The physical structure of my piece changed form multiple times. What I knew for certain from the previous semester was that I wanted to create an encompassing space for the viewer, a semi-circle screen that blocked off what was happening around it, and allowed the viewer to be entranced within a projected space that formed all of their peripheral vision. The idea of the space being an illuminated screen was stimulated by Maya Lin's design for the Vietnam War Memorial. A screen can connote shelter, show protection, as well as be an object to hide something from sight (Sturken, 1991, p. 118). A screen is also a surface or body that can be projected upon and offered as substitute to conceal physical, virtual or emotional material (Sturken, 1991, p. 118). The element of projection added to this emotional material, as shedding light is seen as uncovering knowledge (Sachse \& Guzman, 2010). We situate light with that of bringing insight to a situation, which can often be recollected with memory.

I challenged this notion of distortion created from the folds of the curtains. It was important for me to project the imagery onto the material of curtains, as it also signified the environment of the living room. Specific curtains that replicated the texture of a digital screen further conveyed the reinterpretation of the media. The tactility of material such as cloth brings 
forth notions of warmth, humanity and family (Hawkins, 1993, 759). Fabric is then used as a signifier of home. It is a signifier of clothes that may have been worn by the deceased, invoking feelings of security, warmth and closeness.

For the environment of my structure, I dabbled in the idea of having a sandscape within the midst of the semi-circle, where people can sit and contemplate the video being projected, while leaving a trail of footprints behind. The scene would then allow the next viewer to witness these footprints, and thereby emphasize my idea of absence through presence. Sand also signifies earth, which connotes the ground in which we get buried and return to dust. (Hallam \& Hockey, p. 164). The material of sand has an elemental connotation: the element of earth. The sand used within this context would create a surreal environment, which would confuse the viewer of where the recalled event has taken place. This material as an environment was vetoed as the concept was too abstract for the viewer to understand the connection to the video.

After that I realized that for me to be clear enough on my intention of what I wanted the space to reconstruct - an emotional experience conveyed to the viewer from the memories of the author-I had to display where these memories were created. Most video footage happened in my living room, and it made sense to replicate this environment for my display (See Figure 12). The warmth of home resurfaced as the targeted sentiment I wanted to evoke. This type of resurfacing of memory through place has been done by Shimon Attie (2003) for his series, The Writing on the Wall, where he projected imagery of a neighborhood onto a former Jewish Quarter, expresses the vanishing Jewish culture of post World War II (Attie, p. 75). 


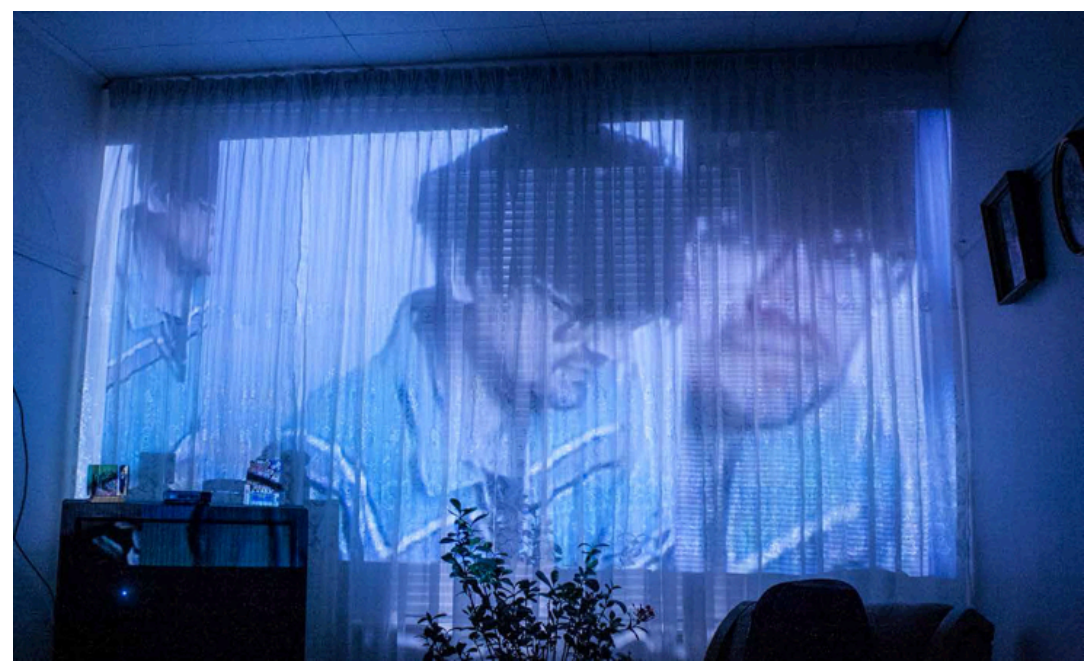

Figure 12. Projected current work in environment.

After testing the projection of my video in my own living space, I decided to use most of all the objects within my own living room for the created semi-circle installation. What was added to my installation were books that were reminiscent of my father, notes from his sketchbook, a potted plant, and three photographs (one portrait of him, one of him and myself, and a family portrait) (See Figure 13). Objects carry sentiment and could embody a certain period of time, such as through a memento mori (Hallam \& Hockey, 2001, p. 51). These objects can be seen as signs of mortality, for example, natural greenery such as flowers and trees. (Hallam \& Hockey, 2001, p. 51). The light and imagery of the projection then catches upon the objects, as fragments of memories move on them. The objects could then be held, looked through, touched and sensed. 


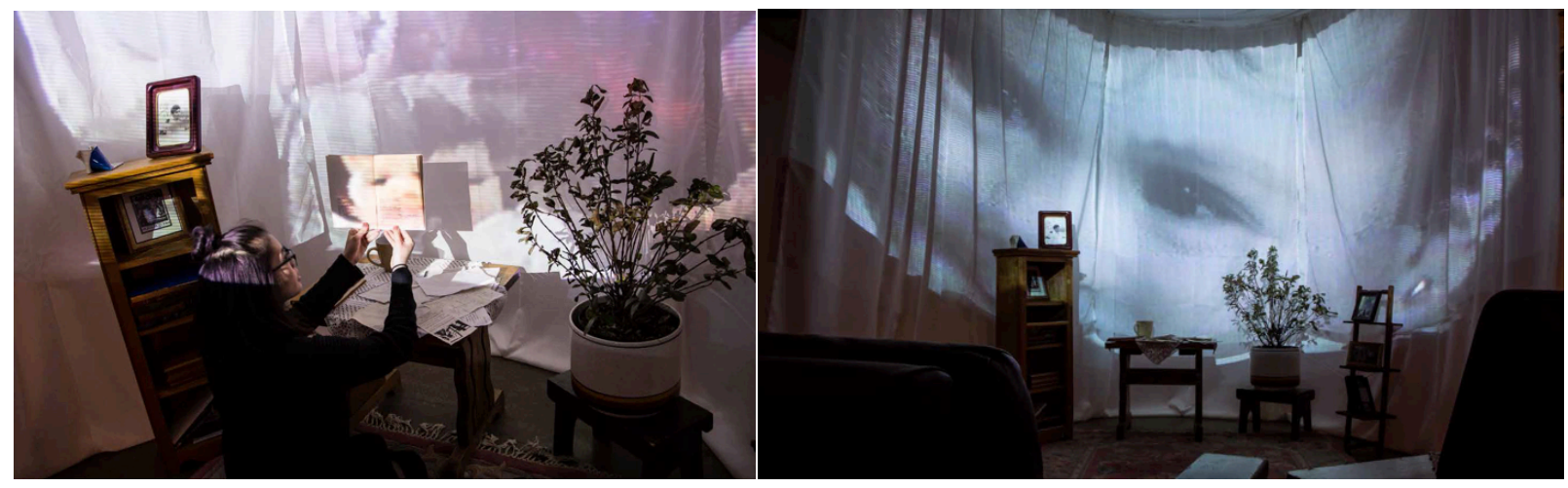

Figure 13.1. \& 13.2. A Constant Revise (2014), Exhibition space.

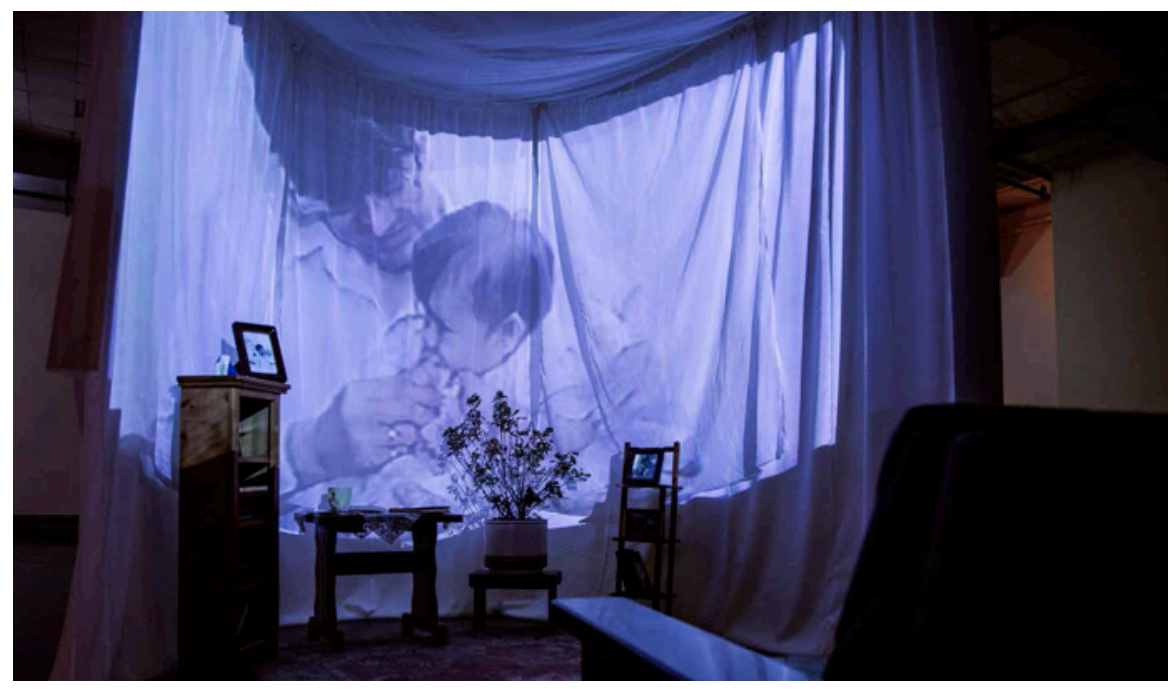

Figure 13.3. A Constant Revise (2014), Exhibition space.

My research question, "How does time, the loss of memory and change in perception alter the identity and knowledge of a departed loved one?" has been addressed through my installation $A$ Constant Revise (Petkovic, 2014). By using a semi-circle encompassing screen, the memory of a past loved one is experienced with the use of material, household objects, and video projection. The absence of a loved one is expressed through repeated presence in a reinterpretation of a family's video archive. The notion of time and environment is reshaped 
through the alteration of media, the narrative of film, questioning what occurred, what is restructured and what is truth.

To say this project is complete would be to say that my memories are eternal. Although $A$ Constant Revise (Petkovic, 2014) gives a good abstraction of my family's archives and my perspective on them, it was only for that specific point in time (2013-2014), for that specific moment in my mourning process. My work would have been completely different if it was created years earlier, closer to his death. How I now mourn my father is quite different, as more memories have faded, more acceptance has been reached, yet now I mourn more for even just the memories of my father, instead of him himself. I have come to terms that this project will never be fully complete, as my perception and memory continues to change and new ideas emerge. New work will further be explored, as mourning itself can be a life-long commitment. In Part 2, I will describe my mourning process further in-depth as a meaning-making process to accept my father's death, and the embodied effect of my interactive installation. 


\section{References}

Attie, S. (2003). The Writing on the Wall, Berlin, 1992-93: Projections in Berlins Jewish Quarter. Art Journal, 62(3), 74-83.

Cardiff, J. \& Fleming, M. (2001). A Large Slow River. Oakville, Ont. Oakville Galleries, Print and Digital Sound File.

Chioua, B., Delbosc, O., Maraval, V., \& Missonnier, M. (Producers). Noe, G. (Director). 2009. Enter the Void. Wild Bunch Distribution.

Colson, C. (Producer) \& Boyle, D. (Director). (2013). Trance. Cloud Eight Films/Fox Searchlight Pictures.

Deleuze, G. (1991). The Fold. Yale French Studies, (80), 227-47.

Dilnot, C. (2008). The Critical in Design (Part One). Journal of Writing in Creative Practice, 1(2), 177-189.

Dorje, G. (Translator). (2007). The Tibetan Book of the Dead: First Complete Translation. Penguin Publishing Group.

Eco, U. (1989). “The Poetics of the Open Work.” In The Open Work, 1-23. Harvard University

Press.Hallam, E. M., \& Hockey, J. L. (2001). Death, memory and material culture. Oxford: Berg.

Hawkins, P. S. (1993). Naming Names: The Art of Memory and the NAMES Project AIDS Quilt. Critical Inquiry, 19(4), 752-779.

Jung, C. G. (1968). Man and His Symbols. Dell Publishing Co., Inc.

Lijn, L., \& Mellor, D. (2005). Liliane Lijn: Works 1959-80. Coventry: University of Warwick.

Lotz, C. (2004) "Recollection, Mourning and the Absolute Past: Husserl, Freud and Derrida," in New Yearbook for Phenomenology and Phenomenological Philosophy, 4, 121-141.

Marker, C. (Director). (1983). Sans Soleil. Argos Films.

Petkovic, Tatjana. (2014). A Constant Revise. [Interactive Installation] Toronto: Beaver Hall Gallery.

Sachse, R. (Producer). Guzman, P. (Director). 2010. Nostalgia for The Light. Icarus Films.

Sturken, M. (1991). The Wall, the Screen, and the Image: The Vietnam Veterans Memorial. Representations, 35(1), 118-142.

Todd, J. \& Todd, S. (Producers). Nolan, C. (Director). 2000. Memento. Newmarket Films/Summit Entertainment. 


\section{Part II}

Introduction

A Constant Revise (2014) is an installation aimed, above all, at being a personal exploration for me, but I believe the viewers could find value within it and extract their own meaning from my piece. This part reflects on my installation, A Constant Revise (2014), by asking how my represented experience of mourning can be beneficial for the viewer. Here I analyze my project through a phenomenological and socio-psychological lens. Firstly, I discuss how my piece is a recreation of my own personal world and how my personal-based form and content affect the viewer. Secondly, I focus on how the installation stimulates processes of empathy, and thirdly, I explain how the creative process of my installation was valuable to me and how this process could benefit others. In section 1 and 2, I will contend that the signs and symbols of my installation help create an embodied experience for the viewer.

\section{Section I. Entering The Author's Personal World}

A Constant Revise (2014) uses a semi-circle 10-foot curtain that functions as a screen for the memories of the author as it surrounds the viewer physically and visually. For this section I ask, how does the installation portray my own personal world? I would define my personal world within this installation as being a shared space of my relationship with my deceased father. I will describe the phenomenological aspects of this space as well as how the signs within the installation help to place the viewer into the embodied experience within my personal "world".

The semi-circle screen of $A$ Constant Revise (2014) can be seen through a phenomenological lens as a surrounding world of a subject (Husserl, 1913, p. 195). It does this 
by intentionally situating the viewer into my personal "world" of a relationship with my father, experienced through the creation of a physically fabricated space (i.e. living room scene) and a constructed internal space (i.e. the video of memory) (Husserl, 1913, p. 196). The surrounding world is created through a semi-circle curtain about ten feet tall, that encompasses the viewer on three sides of them into my personal memories of my relationship of my father. The viewer is able to interact with the objects within the installation, such as reading or moving my father's notebooks with his handwriting, looking through objects and books on the shelf, sitting on the armchair, and smelling the empty coffee cup on the table. The projected video is playing on the curtains of the semi-circle living room space, positioned to surround the viewer's peripheral vision. The video showcases my family's archives, which are edited by me to represent my current perception on my memories of my father and family. My personal experience is seen through video, material, and objects to play with the viewer's emotions, perception, and senses in that moment (Husserl, 1913, p. 196). The aspect of the home I shared with my father is a representation of my relationship with my father. The warmth, familiarity and the protective nature of my living room space creates associations with my memory and connection to my father (Bachelard, 1994, p. 9). His objects (books, journals with his handwriting, shelves) and figure (through video and photographs) are seen prominently within the space. The installation becomes a shared space between my father and I, through various signs, symbols, and memories of our relationship.

What this then does is give the viewer a value-perception, using the intuition of the viewer to perceive and become aware of this surrounding world (Husserl, 1913, p. 196). By physically placing the viewer into my personal surrounding world, the viewers empathize for my situation because of their own surrounding world co-residing with mine in that moment. This is 
done through the video showcasing my perception of my memories within the semi-circle curtained off space that surrounds them. This is also perceived through the objects that make up my living room within the space, family photos, as well as my father's handwriting to signify a home with him. The viewer is able to sit in the armchair just as I am able to, or my father was able to, or to touch the shelves that I have also touched many times. The viewer interprets my perspective through the fabricated space of my interactive installation which represents my personal home shared with my father. The surrounding world is always becoming and transforming based on the subject's perception, and this co-residing with my "world" becomes a natural state of experience (Husserl, 1913, p. 196). The viewer then naturally starts to perceive an experience by physically moving through the space and being in close proximity to it. This is done through the many signs and symbols signifying my perspective within the curtained enclosed space surrounding them. Therefore, the signs and symbols of my installation help create an embodied experience for the viewer that can prompt empathy.

The installation of $A$ Constant Revise (2014) uses quite a few signifiers to compound various layers of meaning and references, implied by different elements of the installation. The signs and symbols of the elements of the installation help drive the viewer to my personal "world". The material objects of the space carry personal associations and memories, as they can represent interests, values, and beliefs (Hallam \& Hockey, 2001, p. 79). For example, the installation space held many books and journals belonging to my deceased father, as well as pages of his personal poetry, indicating his identity based on his subjects of interest, values expressed through his poetry, as well as beliefs in the types of books he owned (Hallam \& Hockey, 2001, p. 79). My father's handwritten journals are emotionally charged material, as they carry memories based on his relationships to others and signify his personal identity, as it is a 
unique form of writing (Hallam \& Hockey, 2001, p. 212). The space itself is a created replica of an intimate personal space of dwelling, one that was continuously used by my deceased father and I. This signifies our relationship to one another, and carries the memory of that relationship (Hallam \& Hockey, 2001, p. 212). The different senses being activated from the installation also play a role in establishing this world. The video projection and the space construction provoked the viewer's sense of sight and sound, the objects within the room that the viewer could go through or sit within, prompting their sense of touch, with the half-empty coffee cup providing a sense of smell. These objects are index signs of my father's identity. The various senses that could be triggered when walking through $A$ Constant Revise (2014) allowed the viewer to better imagine my memories (Neimeyer, 2015, p. 70).

Different material and objects within the installation connote different meanings. The material of cloth for curtains is an index sign of warmth and familiarity (Hawkins, 1993, p. 759). Their long and white frame forming the semi-circle space can allude to church architecture or windows, as well as remind of the white walls often represented as the passage to an afterlife. The "screen" of the semi-circle space is a symbol of a mirror or a dimension of a person's identity or memory. The video being projected is a symbol of my personal memories, and a symbol of my memory process that is an interpretation of my father's death through the rewatching of my family videos. My father's images seen in the photographs in the installation space and the projected video are an iconic sign of him. The journals of my father's handwriting act as indexical signs to his identity and presence. The edited projected video attempts to express the absence of a loved one through their repeated presence; acting as an indexical sign of absence. This was communicated through placing visual focus on their face, which slowly becomes more abstracted and less pronounced when the image is repeated. The deceased loved 
one's face gets larger and frozen in certain clips, which then signifies the viewer's memory processing the image. The processing of image represents the grief stage of questioning the truth of the death of the person (Neimeyer, 2015, p. 70). The VHS media technology is highlighted in the video, as the television texture from the VHS media is prominent throughout the film. The use of this technology is an index sign for a certain type of obsession with the past, temporal to a particular time, as VHS tapes are no longer used (Hallam \& Hockey, 2001, p. 205).

The signifying capacity of the representation of my personal world and my relationship with my father in A Constant Revise (2014) prompts the viewer into a phenomenological experience to perceive my world through an embodied state. Due to the many signifiers to represent different areas of meaning, the viewer may or may not pick up on all of these symbols, but could create their own personal interpretation of my personal world. It is the interpretation of the viewer that creates meaning and value, but for this interpretation to take place, the work needs to be experienced (Sontag, 2009, p.4). The phenomenological experience may not be one that the viewer necessarily understands based on all the different symbolic meanings hidden within it, but is still one for the viewer to experience.

\section{Section II. How Empathy is Created}

Our identities can be represented through the physical places we inhabit, such as our homes. For this section, I will illustrate how the world of the interactive installation, $A$ Constant Revise (2014), can facilitate possible experiences of empathy for the viewer through the creation of the surrounding "world". I will explore the question, how does the personal experience become relatable to others? I will answer the question from a phenomenological lens. 
A Constant Revise (2014) is constructed through a combination of the semi-circle screen, the video of memory, and the objects of my father's identity, which can be seen as my personal surrounding shared "world" with my father. Husserl (1913) describes how empathy can be stimulated in a surrounding "world":

And the personal Ego "relates" to this world in acts upon which it can reflect, as is the case, for example, when it takes notice of itself as personal Ego, just as any other person can reflect on these same acts, even if in a correspondingly modified way (reflection in empathy), when the other grasps these acts as acts of the person in question, for instance whenever the other speaks, with clear understanding, of that person precisely as a person. (Husserl, 1913, p. 195).

Husserl then contends that another person then enters someone else's surrounding world can prompt empathy through reflection of the author's acts, and if understanding is reached. The installation is a created "world" that represents my personal memories and my relationship with my deceased father, which can stimulate empathy within the viewer.

The signs and symbols of the installation can bring forth personal memories as well as connect to the viewers if they also experienced a death of a loved one, have a similar upbringing, share a similar living room environment, objects in common that connote different personal memories specific to them, or comparable family home videos. Even if the viewer does not have these things in common, they might still feel a connection to my personal "world" based on just having any kind of family or loved ones, or appreciating my personal experience. The use of the VHS media format connects to many people who grew up in that specific time period and forms a type of collective memory to that form of media and content (Hallam \& Hockey, 2001, p. 205). These common objects, technology, images and symbols create a collective memory, defining a 
culture (Tutter \& Wurmser, 2016, p. 17). This type of collective memory triggers further empathy, as the shared images connect the viewer to the past and to society (Tutter \& Wurmser, 2016, p. 17). The signs within A Constant Revise (2014) therefore helps drive the phenomenological experience for the viewer to perceive the installation with their body and feel empathy for my personal experience, even if they do not understand every symbol or meaning within the piece.

Different forms of empathy could take place within A Constant Revise (2014) because the narration of my memories is absent, and allows for more open interpretation. These types of empathy can either be explicit simulation empathy, re-enactive empathy or radical empathy.

Explicit simulation empathy can have the viewer place themselves into my own shoes, and have them experience $A$ Constant Revise's (2014) world as their own by connecting their personal memories to mine (Ratcliffe, 2012, p. 475). This is more likely to happen if the person has experienced death within their family and has had a similar relationship to their deceased loved one as myself to my father (Ratcliffe, 2012, p. 477). Ratcliffe (2012) describes re-enactive empathy, also known as mirror empathy and reconstructive empathy as "where various cognitive resources are consciously used to reconstruct the person's experience, enabling a more sophisticated appreciation of her mental life and behavior" (p. 475). Ratcliffe (2012) rejects simulation empathy and re-enactive empathy as it still creates a separation between the viewer and the author, because the viewer can still differentiate that the story is unique to the author and not themselves (2012, p.475). I would argue that these types of empathy can still be prompted in my installation through various elements such as space, objects, and narrative to communicate my memories described in Part 1. The signs and symbols of the installation help prompt both reenactive empathy and explicit stimulation empathy. However, I acknowledge that simulation 
empathy and re-enactive empathy are not phenomenological empathy, so an embodied experience may not be present in the viewer. Merleau-Ponty (1996) describes how this interpretation can be seen; "rather than seeing it, I see according to, or with it" (p. 126). This type of experience has a viewer perceive my world not only through their experience, but also through their own understanding of my experience.

A Constant Revise (2014) can also prompt radical empathy, which is when the viewer is more open and willing to be affected by a work or person (Ratcliffe, 2012, p. 488). The interactive installation is situated in a gallery space, where a viewer must decide and consciously enter, and move through in order to get to the installation. This in turn, means the viewer is more open and willing to interact with an art piece or environment. Radical empathy also allows for the viewer to have their perspective of the world reshaped when they interact, such as if they experience the author's world (Ratcliffe, 2012, p. 488). The viewer's experience is affected by my experience, which prompts them to consider my perspective, and therefore, creates empathy. This allows the viewer to feel as though they belong to a shared world with me by entering my interactive installation and experiencing it (Ratcliffe, 2012, p. 491). An interpretation of this interaction by the viewer is also necessary, as it allows the viewer to reflect on the experiential insight of how the author's world is like, inciting appreciation and empathy (Ratcliffe, 2012, p. 488). Radical empathy can also be stimulated if the viewer has not experienced a similar feeling of grief, as they can then still appreciate my personal experience (Ratcliffe, 2012, p. 490). Therefore, radical empathy can be triggered in A Constant Revise (2014) based on the viewer's willingness and openness to being affected by my experience.

In summary, empathy can be prompted within A Constant Revise (2014) through the signs and symbols of the installation, as well as the immersion into the shared world of my 
relationship with my father. Explicit simulation empathy allows the viewer to compare their memories with my own. Re-enactive empathy is possible through the reconstruction of my personal experience through my projected video, allowing the viewer to appreciate the simulation of the installation. Radical empathy is dependent on the openness and willingness of the viewer interacting with the installation, and can affect anyone who would let their participation reshape their perspective.

\section{Section III. Reflection on My Mourning Process Through Meaning-Making}

Addressing the initial question of my project, "How does time, memory and change in perception alter the identity of a departed loved one?" helped me understand my own relationship with my father and become aware of how my own identity changed through his death. For this section, I will attempt to answer how the process of meaning-making helps me go through my mourning process. By developing this reflection, I want to show how, through meaning-making, others could also potentially cope with the loss of their loved ones.

Initially, I worked out my project's visual exploration and creation as a type of selftherapy that would help me cope with the loss of my father. The process made me learn more about my relationship with my father, how family archives affect us, how important it is to try and remember and document moments, how important it is to share work to facilitate conversation, and how nothing is permanent.

The process of looking through family photos and video archives made me remember and better understand my relationship with my father. It made me verify that he did exist, and helped me reestablish our relationship. Imagery prompts this process as it allows us to connect through 
our senses of sight to perceive the deceased as real, and our relationship to them as real (Neimeyer, 2015, p. 70).

Through my project, I visually represented how time affected my mourning process with my father. I tried to focus on how time affected my memory of our relationship, such as me forgetting my conversations with him, forgetting his gestures, voice and movements. The idea to keep mementos and pictures of my father was prominent to sustain my relationship with him (Neimeyer, 2015, p. 70).

I never fully accepted my father's death because it was sudden and it took place when I was young. I had barely touched pictures and videos of him until actively deciding to go through a meaning-making process as my thesis project. What prompted me, was to keep his memory alive, so that I could remember him in greater detail. Creating a video that encompasses my memories and processing the reality of our relationship allowed me to develop a story of events and observe my relationship with him, connecting them to positive aspects of our relationship through symbols and signs (Gershman, N., 2015, p. 206). By creating a type of "dreamscape" about our relationship, I was able to understand a larger perspective on my father's death through the process of meaning-creation. A "dreamscape" creation allowed me to make associations between past, present, future and fantasy.

Furthermore, by sharing my process in a gallery show with my friends and family, I was able to experience a "second round of healing", reminiscing about my father with close loved ones (Gershman, N., 2015, p. 206). The idea of the "dreamscape" method has two aims, 1) to shift the mourner's perspective of their deceased loved one to a supportive presence, instead of an absent supporter, and 2) to provide the mourner with a physical object that reinforces this shift in perspective (Gershman, N., 2015, p. 206). By making associations of imagery with positive 
memories, it allows the griever to become more invested in their own healing process (Gershman, N., 2015, p. 208). From my personal experience, I tried to make sense of both negative (actual depictions from the funeral), to neutral (different scenes with my father), to positive (photographs and video of me embracing my father), and I found that my more positive associations did give me more relief, and made me feel closer to my father. Gershman discusses potential questions that the mourner can ask when brainstorming for creating their dreamscape, such as "What do you think [the deceased] would want you to do now in terms of changes/goals? What would [the deceased] say about the current state of affairs (i.e., his/her death)?" (2015, p. 208). I did not really consider these questions when creating my "dreamscape", but I did ask myself, what would I tell my father now? The process of reflecting on these types of questions helps a mourner consider their relationship and bond with the deceased (Gershman, N., 2015, p. 208). The creation of my narrative of memories allowed me to continue my bond with my father, maintaining a relationship with him after his death. I believe art as a meaning-making process helped me through my grieving process, and allowed me to better understand my father's death, our relationship, and how my identity changed after his death.

\section{Conclusion}

Through allowing the viewer to embody and experience my personal "world", it prompts them to feel empathy for my experience, and either shares those emotions as if they are experiencing it for themselves, or shifting their own perspective on the mourning process. Different forms of empathy can be prompted, such as simulation empathy, re-enactive empathy or radical empathy. The signs and symbols within A Constant Revise (2014) help stimulate an embodied experience 
for the viewer, encouraging them to feel empathy. The viewer is able to take away their own unique experience from A Constant Revise (2014). Everyone in this world will eventually pass away, and by pre-emptively having others better understand someone else's mourning process, it can better help them reflect on their own when they do experience it themselves.

This specific installation may be used by mental health organizations such as CAMH to raise awareness of the mourning experience, and engage audiences in understanding different methods of mourning the dead. The installation can also facilitate discussion with other onviewers experiencing it, allowing for more open dialog on grief, and allow for a widening of perspective on personal reflection.

My own personal experience with creating art as a meaning-making process allowed me to accept my father's death, understand my changed identity after my father's death, and continue my relationship with him. 


\section{References}

Bachelard, G. (1994 [1958]) The Poetics of Space: The Classic look at how we experience intimate spaces, Boston: Beacon Press.

Gershman, N. (2015). Prescriptive Photomontage. Techniques of grief therapy: Creative practices for counseling the bereaved. New York: Routledge. 205-210.

Hallam, E. M., \& Hockey, J. L. (2001). Death, memory and material culture. Oxford: Berg.

Husserl, E. (1913). The Person as Center of a Surrounding World. Ideas II. Studies in the Phenomenology of Constitution. 194-199.

Merleau-Ponty, M. (1996). Eye and Mind. In The Merleau-Ponty aesthetics reader: Philosophy and painting (G. A. Johnson, Ed.), (pp. 121-164). Evanston, IL: Northwestern University Press.

Neimeyer, R. A. (2015). Techniques of grief therapy: Creative practices for counseling the bereaved. New York: Routledge.

Petkovic, Tatjana. (2014). A Constant Revise. [Interactive Installation] Toronto: Beaver Hall Gallery.

Radcliffe, M. (2012). Phenomenology as a Form of Empathy. Inquiry, Volume 55 (5), 473-495. Routledge.

Sontag, S. (2009). Against interpretation and other essays. London: Penguin.

Tutter, A., \& Wurmser, L. (2016). Grief and its transcendence: Memory, identity, creativity. New York: Routledge, Taylor \& Francis Group. 


\section{CONCLUSION}

Utilizing interactive installations as a form of art therapy for mourners would create an embodied reflective experience, and would provide them with access to a community that prompts discussions on grief. This is necessary as the mourner goes through a difficult period of coming to terms with the death of their loved one. The mourner is in a process of seeking meaning in order to understand their current situation in relation to their loss.

We are constantly surrounded by space and affected by it. The spaces we inhabit represent our personal identities, and our identities shift when a loved one passes away. Our bodies search for our loved ones in the spaces they once used to inhabit with us. Our bodies try and make sense of the situation through specific spaces, such as attending ceremonies and rituals to help distinguish that our loved ones no longer reside in our shared homes with us. When mourning the loss of a loved one, the body searches for meaning within different spaces to understand the mourner's changed identity without their deceased loved one.

Time affects the mourner as they feel stuck between two time periods, the present and the past with their loved one. The mourner's perception of time creates a false sense of reality, which prompts them to search for meaning to accept their loss. The passing of time helps the mourner accept the loss, as it emphasizes the absence of their loved one by the repeated occurrence of not seeing their physical presence. Our memories of our loved ones make up our own identity, and their death prompts us to reshape our current sense of self.

Art can be used as a meaning-making process to help mourners accept their loss, and sustain their relationship with their departed loved one. Our experience with art is one that affects our mind and physical body while experiencing a feeling of embodiment through the 
physical act of making and experiencing art. Different art forms such as visual art, poetry, performance, etc. can aid a mourner through their grief, as it provides them a wider scope of expression then verbal language, giving them an outlet to express a difficult emotion or situation. The mourner can use art to help visualize and process their current reality, express their emotions, understand their new identity without their loved one, and maintain a relationship with the deceased.

Interactive art installations have been shown to have positive effects on society, as people can interact with the work and create shared experiences with other viewers. Mourners specifically are able to reflect on their personal grieving process and acquire a new space for discussion on their very personal and difficult situation. Spaces that are specific to death, such as interactive installations on mourning, can create a sense of community between mourners through the use of physical shared space and objects of memory (Hallam \& Hockey, 2006). The aspect of space, alongside the signs and symbols within an interactive art installation creates an embodied experience to take place, better illustrating the mourning process.

My interactive installation A Constant Revise (2014) is an example of a non-traditional way to mourn the loss of a loved one in our current time. A Constant Revise (2014) can be used by mental health organizations such as CAMH (The Centre for Addiction and Mental Health) to raise awareness of the mourning experience and engage audiences in understanding different methods of mourning the dead. This installation can also facilitate discussions with other viewers amongst themselves, allowing for a more open dialog on grief. This can then promote a wider perspective on reflections with personal death and grief. By allowing the viewer to embody and experience my personal "world", the installation prompts them to feel empathy for my experience, and either share the emotion if they experienced a similar situation, or appreciate 
mine by understanding my experience. Specifically, radical empathy can generate a better understanding of my experience and reshape the viewer's perspective on the emotions and process of mourning (Radcliffe, 2012). The viewer is able to take away their own unique experience from $A$ Constant Revise (2014) based on their perception and experience of the installation.

The death of a loved one will someday affect everyone. By learning and sharing stories on grief, mourners are able to better understand their own grieving process. Art and meaning making can help aid mourners in their acceptance of death, and sustaining the relationship with their deceased loved ones. Those who have not experienced mourning yet, may still empathize with someone else's mourning process, and recognize that they will someday have to go through a similar grieving process themselves. This can be seen through the embodied experiences of art, prompting artists and viewers into reflective states, allowing them to process and better understand their current experiences of mourning. 


\section{References}

Hallam, E. M., \& Hockey, J. L. (2001). Death, memory and material culture. Oxford: Berg.

Petkovic, Tatjana. (2014). A Constant Revise. [Interactive Installation] Toronto: Beaver Hall Gallery.

Radcliffe, M. (2012). Phenomenology as a Form of Empathy. Inquiry, Volume 55 (5), 473-495. Routledge.

Urbanowicz, K., \& Nyka, L. (2016). Media Architecture and Interactive Art Installations Stimulating Human Involvement and Activities in Public Spaces. CBU International Conference Proceedings, 4. 591. 